R.

L.

E.

E

C

H

N

I

C

A

L

R

E

P

O

R

$\mathrm{T}$

4

5

4

\title{
PLASMA DIAGNOSTICS
}

J. CHARLES INGRAHAM

SANBORN C. BROWN

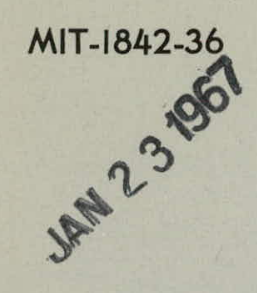

RETIEASED FOR ANNOUWCXWEBS?

IN RUCLEAR SCIENCE ARSTRAERS

TECHNICAL REPORT 454

OCTOBER 3, 1966

MASSACHUSETTS INSTITUTE OF TECHNOLOGY

RESEARCH LABORATORY OF ELECTRONICS

CAMBRIDGE, MASSACHUSETTS 


\section{DISCLAIMER}

This report was prepared as an account of work sponsored by an agency of the United States Government. Neither the United States Government nor any agency Thereof, nor any of their employees, makes any warranty, express or implied, or assumes any legal liability or responsibility for the accuracy, completeness, or usefulness of any information, apparatus, product, or process disclosed, or represents that its use would not infringe privately owned rights. Reference herein to any specific commercial product, process, or service by trade name, trademark, manufacturer, or otherwise does not necessarily constitute or imply its endorsement, recommendation, or favoring by the United States Government or any agency thereof. The views and opinions of authors expressed herein do not necessarily state or reflect those of the United States Government or any agency thereof. 


\section{DISCLAIMER}

Portions of this document may be illegible in electronic image products. Images are produced from the best available original document. 
The Research Laboratory of Electronics is an interdepartmental laboratory in which faculty members and graduate students from numerous academic departments conduct research.

The research reported in this document was made possible in part by support extended the Massachusetts Institute of Technology, Research Laboratory of Electronics, by the JOINT SERVICES ELECTRONICS PROGRAMS (U.S. Army, U.S. Navy, and U.S. Air Force) under Contract No. DA36-039-AMC-03200(E) ; additional support was received from the United States Atomic Energy Commission under Contract AT (30-1)-1842.

Reproduction in whole or in part is permitted for any purpose of the United States Government.

Qualified requesters may obtain copies of this report from DDC. 


\section{MASSACHUSETTS INSTITUTE OF TECHNOLOGY}

\section{RESEARCH LABORATORY OF ELECTRONICS}

H. C. $\$ 3.00 ; \mathrm{MN}=62$

Technical Report 454

October 3, 1966

MIT-1842-36

\section{PLASMA DIAGNOSTICS}

J. Charles Ingraham and Sanborn C. Brown

(Manuscript received May 27, 1966)

1

This report was prepared as an account of NOTTCE

A. Makes any warsion, nor any person actingent sponsored

racy, comples any warranty or repry person acting on behansored work. Nelther of

of any Information, or usefulness of the infon, expressed or Implied, commission:

privately owned rion, apparatus, method, information contained in with respect to the accu-

B. Aged rights; or mocess disclosed in this report, or that accu-

use of any information, appses with respect to the uge of in this report may not infringe

As used in the above, "par, method, or process of, or for damages resulumg trom

ployee or contractor of above, "person acting on becess disclosed in this represulting from the

such employee or cor the Commission, or behalf of the Commiss report.

dissominates, or provideotor of the Commlssion, of such contractor includes any em-

with the Commission, or hiccess to, any informan, or employee of such contr, the extent that

. . or his employment with such pursuant to his employment prepares,

with such contractor. 


\section{TABLE OF CONTENTS}

I. Microwave Plasma Diagnostics 1

1.1 Theory

1.2 Transmission Measurement of Electron Density and Electron Collision Frequency

1.3 Microwave Cavity Measurement of Electron Density and Collision Frequency

a. Relation between Cavity Resonance Parameters and the Electron Density and Collision Frequency

b. Experimental Methods for Measurement of $\Delta f / f_{0}$ and $\Delta(1 / Q)$ of a Resonant Cavity

1.4 Thermal Radiation Measurement of Electron Temperature

II. General Plasma Diagnostic Techniques $\quad 27$

$\begin{array}{lll}2.1 & \text { Plasma Probes } & 27\end{array}$

a. The Langmuir Probe and the Double Floating Probe $\quad 27$

b. RF Plasma Probes $\quad 28$

2.2 Optical Plasma Diagnostics $\quad 28$

2.3 Other Techniques $\quad$. 29

$\begin{array}{lr}\text { Acknowledgment } & 29\end{array}$

$\begin{array}{ll}\text { Bibliography } & 30\end{array}$

$\begin{array}{ll}\text { References } & 31\end{array}$ 


\section{MICROWAVE PLASMA DIAGNOSTICS}

\subsection{THEORY}

The diagnostics of a plasma utilizing electromagnetic radiation transmitted through or emitted from a plasma can be discussed in terms of a simplified theoretical model by employing Newton's second law for the motion of an "average" electron and Maxwell's equations.

A plane electromagnetic wave of frequency $\omega$ and propagation vector $\vec{k}$ can be described by

$$
\vec{E}=\vec{E}_{o} e^{i(\omega t-\vec{k} \cdot \vec{r})}
$$

The propagation vector may have both a real and imaginary part if the wave propagates in a lossy medium. The imaginary part gives the rate of damping of the wave, and the real part is $k_{r}=2 \pi / \lambda$, where $\lambda$ is the wavelength of the wave in the medium.

The equation of motion of an electron acted upon by this wave and also undergoing collisions with surrounding gas atoms, with the use of Newton's second law, is

$$
m \frac{d \vec{v}}{d t}+m v_{m} \vec{v}=-e \vec{E}_{0} e^{i(\omega t-\vec{k} \cdot \vec{r})}
$$

where $\mathrm{m},-\mathrm{e}$, and ${ }^{\mathrm{m}}$ are the electron mass, charge, and collision frequency with gas atoms, respectively. The collisions act as a drag term, removing momentum induced by the applied external fields. A typical value of $v_{\mathrm{m}}$ is that of electrons in helium gas, which for the electrons of temperatures greater than $\sim 12,000^{\circ} \mathrm{K}$ has a value independent of temperature, ${ }^{1} v_{\mathrm{m}}=2.3 \times 10^{9} \mathrm{p} \mathrm{sec}^{-1}$, where $\mathrm{p}$ is the helium pressure in Torr.

If the amplitude of the electrons' resulting oscillatory motion is small compared with the wave, or if the wave is of transverse polarization, $\left(\vec{k} \perp \vec{E}_{0}\right)$, the oscillatory solution for $\vec{v}$ is

$$
\overrightarrow{\hat{v}}=\frac{-e \vec{E}_{o} e^{i(\omega t-\vec{k} \cdot \vec{r})}}{m\left(i \omega t v_{m}\right)} .
$$

The induced oscillatory current density in an electron gas of density $\mathrm{n}$ is

$$
\vec{J}=n(-e) \vec{v} \text {. }
$$

This current density is substituted in Maxwell's equations (rationalized MKS units)

$$
\begin{aligned}
& \vec{\nabla} \times \vec{E}=-\mu_{0} \frac{\partial \vec{H}}{\partial t} \\
& \vec{\nabla} \times \vec{H}=\vec{J}+\epsilon_{o} \frac{\partial \vec{E}}{\partial t}
\end{aligned}
$$

and the magnetic vector $\overrightarrow{\mathrm{H}}$ eliminated to yield 


$$
\vec{\nabla} \times(\vec{\nabla} \times \overrightarrow{\mathrm{E}})=-\mu_{\mathrm{o}} \overrightarrow{\mathrm{j}}-\frac{1}{c^{2}} \overrightarrow{\ddot{\mathrm{E}}}
$$

Under the assumptions that the electric field and current density are determined by Eys. 1 and $3 \mathrm{~b}$, and also that the wave is transversely polarized, we obtain

$$
k^{2} \vec{E}=-\frac{n e^{2} i \omega \mu_{o}}{m\left(i \omega+v_{m}\right)} \vec{E}+\frac{\omega^{2}}{c^{2}} \vec{E} .
$$

For a nonzero solution for $\overrightarrow{\mathrm{E}}$ to be possible, $\mathrm{k}^{2}$ must satisfy

$$
\mathrm{k}^{2}=\frac{\omega^{2}}{\mathrm{c}^{2}}\left(1-\frac{\omega_{\mathrm{p}}^{2}}{v_{\mathrm{m}}^{2}+\omega^{2}}\left[1+\mathrm{i} \frac{{ }^{2} \mathrm{~m}}{\omega}\right]\right) \text {. }
$$

Here, we have set $\omega_{\mathrm{p}}^{2}=\frac{n e^{2}}{\mathrm{~m} \epsilon_{\mathrm{o}}}$. By analogy with optical terminology, the quantity multiplying $\omega^{2} / c^{2}$ is the square of the complex index of refraction of the plasma. The quantity $\omega_{p}$ is the electron plasma frequency which can be expressed as

$$
\omega_{p}=56.4 \sqrt{n} \mathrm{sec}^{-1}
$$

where $\mathrm{n}$ is in units of $\mathrm{m}^{-3}$. It is seen from Eq. 8 that the relative sizes of $\omega_{\mathrm{p}}, \omega$, and $v_{m}$ determine the manner in which the plasma affects the propagation constant of the wave. For instance, in a collisionless plasma with $v_{\mathrm{m}}=0$, the propagation vector is purely imaginary for $\omega<\omega_{p}$ and hence the wave cannot propagate in the plasma. A wave externally incident on the plasma boundary suffers total reflection under this condition.

For cases in which $\omega_{\mathrm{p}}^{2} /\left(v_{\mathrm{m}}^{2}+\omega^{2}\right) \ll 1$ and $v_{\mathrm{m}} \leqslant \omega$, the approximate expression

$$
\mathrm{k} \approx \frac{\omega}{\mathrm{c}}\left[\left(1-\frac{\omega_{\mathrm{p}}^{2}}{2\left(v_{\mathrm{m}}^{2}+\omega^{2}\right)}\right)-\mathrm{i} \frac{\omega_{\mathrm{p}}^{2}}{2\left(v_{\mathrm{m}}^{2}+\omega^{2}\right)} \frac{v_{\mathrm{m}}}{\omega}\right]
$$

is obtained. This shows directly, upon substitution in Eq. 1, how the plasma frequency and the collision frequency affect the wavelength and the damping of the electromagnetic wave. If the plasma density goes to zero, the propagation constant, $k$, reduces to its free-space value, $\omega / c$. Equation 10 also applies at high pressures where $\nu_{m} \gg \omega$, provided the condition $\omega_{\mathrm{p}}^{2} \ll \omega \nu_{\mathrm{m}}$ is satisfied.

The proper expression for $k^{2}$, containing an average of $v_{m}(v)$ over a Maxwellian velocity distribution of temperature $\mathrm{T}$,

$$
f=\left(\frac{m}{2 \pi k T}\right)^{3 / 2} e^{-m v^{2} / 2 k T}
$$


is

$$
\mathrm{k}^{2}=\frac{\omega^{2}}{\mathrm{c}^{2}}\left(1-\frac{\omega_{\mathrm{p}}^{2}}{\frac{3}{2} \mathrm{kT}} \int_{0}^{\infty} \frac{\left(1+i \frac{{ }^{\nu} \mathrm{m}}{\omega}\right)}{v_{\mathrm{m}}^{2}+\omega^{2}} \frac{\mathrm{mv}^{2}}{2} \mathrm{f} 4 \pi \mathrm{v}^{2} \mathrm{dv}\right)
$$

This is seen to be an average over all electron velocities with a weighting factor equal to the electron energy. The correct averages of $1 /\left(\omega^{2}+v_{\mathrm{m}}^{2}\right)$ or $v_{\mathrm{m}} /\left(\omega^{2}+v_{\mathrm{m}}^{2}\right)$ over the electron Maxwellian velocity distribution may be obtained in the following discussions by multiplying these factors by

$$
\frac{1}{\frac{3}{2} k T} \frac{m v^{2}}{2} f 4 \pi v^{2} d v
$$

wherever they appear and integrating over all electron speeds. For the case in which $v_{\mathrm{m}}$ is independent of velocity, Eq. 11 reduces to Eq. 8.

\subsection{TRANSMISSION MEASUREMENT OF ELECTRON DENSITY AND}

\section{ELECTRON COLLISION FREQUENCY}

An electromagnetic wave propagating through a tenuous plasma of length $L$, in which the conditions $\omega_{\mathrm{p}}^{2} /\left(v_{\mathrm{m}}^{2}+\omega^{2}\right) \ll 1$ and either $v_{\mathrm{m}} \leqslant \omega$ (low pressures) or $\omega_{\mathrm{p}}^{2} \ll \omega v_{\mathrm{m}}$ (high pressures) are satisfied, suffers a change of phase

$$
\Delta \phi=-\frac{\omega}{c} \frac{\omega_{p}^{2}}{2\left(v_{m}^{2}+\omega^{2}\right)} L
$$

and, provided there are no reflections, a fraction of the power

$$
\frac{P}{P_{0}}=\left(e^{-\frac{\omega}{c}} \frac{\omega_{p}^{2}}{2\left(v_{m}^{2}+\omega^{2}\right)} \frac{v_{m}}{\omega} L\right)^{2}=e^{-\frac{\omega}{c}} \frac{\omega_{p}^{2}}{\left(v_{m}^{2}+\omega^{2}\right)} \frac{v_{m}}{\omega}
$$

is transmitted.

Provided the plasma is tenuous and the transition from free space to plasma is not too sharp, reflections will not be important. The electron density gradient that exists at the boundary of any plasma helps to make the transition gradual. This transition will be gradual for a tenuous plasma in which the dominant electron loss is by diffusion, provided the dimension of the plasma parallel to the direction of propagation of the wave is large compared with the wavelength. 


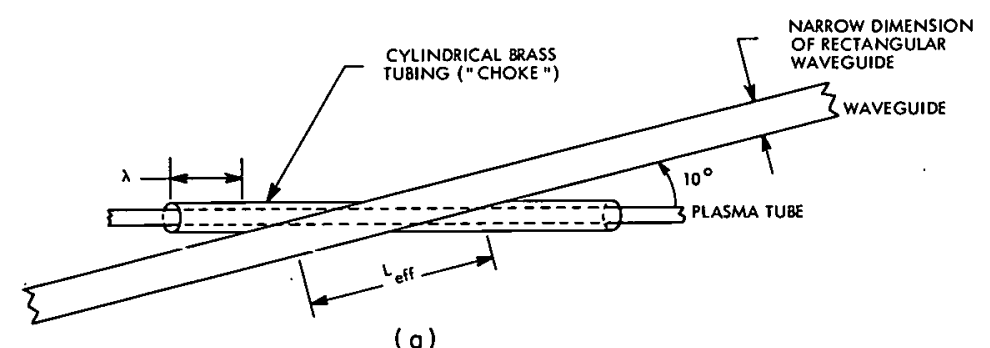

(a)

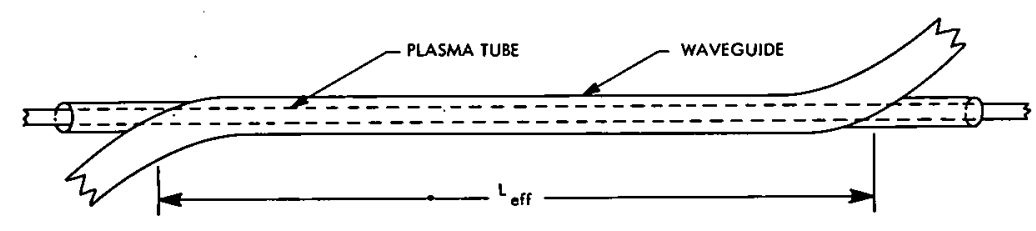

(b)

Fig. 1. Possible plasma tube and waveguide configurations for interferometric study of plasma.

For a plasma contained in a cylindrical glass tube of radius that is small compared with the wavelength, reflections can be minimized when performing the interferometric measurement at microwave frequencies in a waveguide by inserting the tube into the waveguide through openings in the broad face of the waveguide so that the tube and waveguide axes make an angle of approximately $10^{\circ}$ with each other. Figure la is a diagram of such an arrangement. To prevent leakage of the microwave power through the insertion openings, cylindrical brass tubing ("chokes") must be joined smoothly to the waveguide surrounding the opening and must extend approximately one free-space wavelength along the plasma tube. These chokes act as waveguidesbeyond-cutoff ${ }^{2}$ to the microwave signal. If the larger transverse dimension of the waveguide is "a", the inside diameter of the choke should be no greater than approximately a/3. The plasma tube should be made of fused quarz for lowest loss, but Pyrex tubing is satisfactory. Corning glass No. 7070 is a reasonable compromise between these two. The effective length of the plasma is given roughly in Fig. la. A correction factor $\eta$ must be applied to Eqs. 12 and 13 to account for the fact that the plasma does not fill the whole waveguide and for the altered wavelength, $\lambda g$, of the microwave signal as it propagates in the waveguide relative to the free-space wavelength, $\lambda$. For the lowest waveguide mode, $\lambda_{g}=\frac{\lambda}{\sqrt{1-(\lambda / 2 a)^{2}}}$. The result of a first-order perturbation calculation for the phase shift and transmission of a microwave signal through a tenuous plasma that partially fills the waveguide is

$$
\Delta_{\phi}=-\eta \frac{\omega}{c} \frac{\omega_{\text {po }}^{2}}{2\left(v_{m}^{2}+\omega^{2}\right)} L_{\text {eff }}
$$


and

$$
\frac{\mathrm{P}}{\mathrm{P}_{\mathrm{o}}}=\mathrm{e}^{-\eta \frac{\omega}{\mathrm{c}}} \frac{\omega_{\mathrm{po}}^{2}}{\left(v_{\mathrm{m}}^{2}+\omega^{2}\right)} \frac{v_{\mathrm{m}}}{\omega} \mathrm{L}_{\mathrm{eff}}
$$

where

$$
\eta=\frac{\lambda}{\lambda_{g}} \frac{2}{a b} \int_{x=0}^{x=a} \int_{y=0}^{y=b} \frac{n(x, y)}{n_{0}} \sin ^{2} \pi x / a d x d y
$$

and

$$
\omega_{p o}^{2}=\frac{n_{o} e^{2}}{m \epsilon_{0}} .
$$

Here, $\mathrm{n}_{\mathrm{o}}$ is the maximum electron density. The integration is over the waveguide cross section, $a$ and $b$ being the broad and narrow dimensions, respectively. If the plasma is uniform and fills the whole waveguide, $\eta$ reduces to $\lambda / \lambda_{\mathrm{g}}$. For a plasma of radius $\mathrm{R}$ 《 $\mathrm{a}$, which is centered in the waveguide and in which the electron density.is uniform, $\eta \approx$ $\lambda / \lambda_{g}(2 / a b)\left(\pi R^{2}\right)$. A typical value for $\eta$ in an experimental geometry such as is shown in Fig. $1 \mathrm{a}$ is 0.2 .

To insure that the plasma is tenuous to a microwave signal of $3000-\mathrm{Mc}$ frequency in the low-pressure case, where $\nu_{m} \leqslant \omega$, we must require that $\omega_{p} \ll \omega$, which with the use of Eq. 9 give the result that the electron density must be much less than $10^{11} \mathrm{~cm}^{-3}$, or approximately less than or equal to $3 \times 10^{10} \mathrm{~cm}^{-3}$. The minimum detectable density, $\mathrm{n}_{\text {min' }}$ is determined by the minimum detectable phase shift, which typically will be $\approx 0.02$ radian. Thus, for $L_{\text {eff }}=30 \mathrm{~cm}, \eta=0.2$, and a $3000-\mathrm{Mc}$ probing signal, $n_{\min }$ ' from Eq. 14, is equal to $10^{9} \mathrm{~cm}^{-3}$. Figure $1 \mathrm{~b}$ shows an experimental arrangement whereby $L_{\text {eff }}$ may be increased so as to further reduce $n_{\min }$. A combined phase shift and absorption measurement give both $v_{\mathrm{m}}$ and the electron density.

An absorption measurement sensitive to a 1 per cent absorption, under the experimental conditions just described, could detect an absorption at $n=n_{\min }$, provided $\nu_{\mathrm{m}} / \omega \geqslant$ 0.25. Thus, for gas pressures with $v_{\mathrm{m}} \approx \omega$, a more sensitive measurement of the electron density could be obtained from the absorption measurement, provided $v_{\mathrm{m}}$ were known. At $3000 \mathrm{Mc}, v_{\mathrm{m}}=\omega$ in helium gas at a pressure $\approx 8$ Torr.

For high gas pressures with $v_{\mathrm{m}} \gg \omega$ the experimental limitations are altered. At 1 atm pressure in helium and for a 3000-Mc signal, $\mathrm{v}_{\mathrm{m}} / \omega \approx 100$. The maximum electron density consistent with the tenuous-plasma condition $\omega_{\mathrm{p}}^{2} \leqslant\left(\frac{1}{3}\right) \nu_{\mathrm{m}} \omega$ is $\mathrm{n}=3 \times 10^{12} \mathrm{~cm}^{-3}$, and the electron density corresponding to a 1 per cent absorption for $L_{\text {eff }}=30 \mathrm{~cm}$ and 
$\eta=0.2$ is $\mathrm{n}=3 \times 10^{10} \mathrm{~cm}^{-3}$. The phase shift at the maximum allowable electron density under these conditions is only approximately 0.01 radian, and does not provide a useful means of density measurement. Hence $v_{m}$ must be known if the electron density is to be determined from an absorption measurement at high pressures. Measurements at high pressures can be affected by absorption and phase change caused by the gid molecules present. If this effect were large, of course, it might be utilized as a means of identifying molecular species.

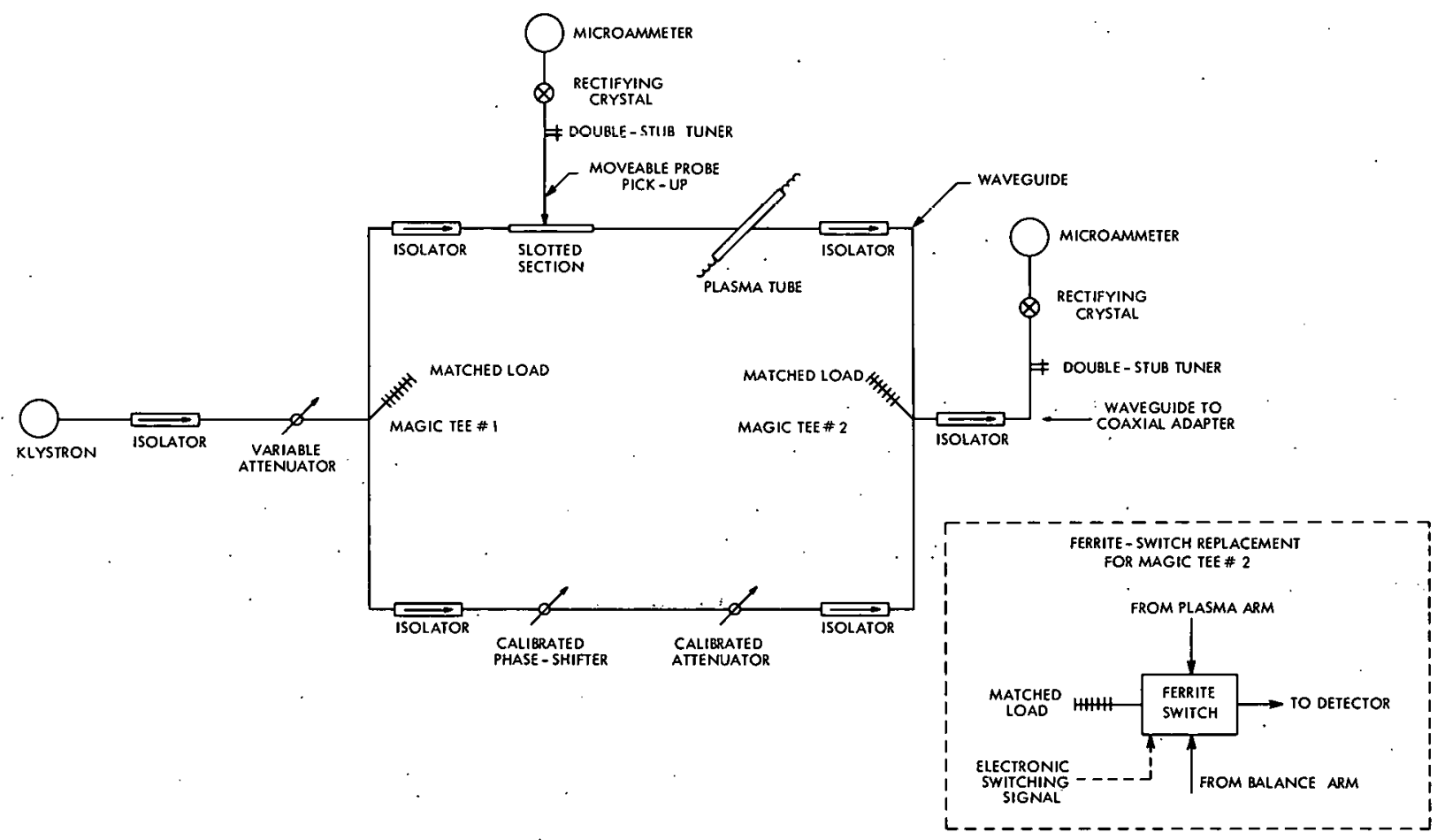

Fig. 2. Microwave interferometer. Inset: modification of bridge for absorption measurements alone.

Figure 2 is a schematic diagram of a microwave interferometer bridge. The signal is generated by a klystron oscillator and split into two equal parts, one part passing through the plasma and the other part through a compensating arm that is adjusted so as to introduce a phase shift and attenuation such that the signals when recombined produce a null reading on the microammeter detector. The difference between the null settings of the phase shifter and attenuator when the plasma is off and when it is on, equals the absorption and phase shift introduced by the plasma. It is important that reflections from the plasma be negligible in order that a true absorption be measured. The slotted section shown immediately preceding the plasma tube can be used to monitor the standing-wave ratio, because of reflections from the plasma. Measurements on the behavior of a time-variant plasma can be made by replacing the microammeters 
by an oscilloscope.

The magic tee is a four-port waveguide component that divides the microwave power entering it equally between the two exit arms, or that recombines two signals entering the appropriate pair of its arms and sends half of each signal into each of the other two arms. The isolators are used so as to allow the microwave radiation to propagate only in one direction in the waveguide, thereby minimizing leakage of the microwave signal between the arms of the bridge and effects arising from reflections from the plasma.

In order to increase the sensitivity, the klystron power can be square-wave modulated and the microammeter replaced by a synchronous detector, which is sensitive only to signals having the phase and frequency corresponding to the klystron modulation signal. These detectors are commercially available. They are of considerably greater importance when applied to the measurement of very low power signals such as are encountered in measuring the microwave emission from the plasma itself, as discussed below.

When only plasma absorption is to be measured an increase in convenience can be obtained by replacing magic tee No. 2 of Fig. 2 (see Fig. 2 insert) by a four-port ferrite switch. This switch send the signals from the two bridge arms alternately into the detector arm so that an accurate balance of the plasma absorption, independent of phase shift, may be obtained by using a synchronous detector or oscilloscope. As discussed below, the power isolation between the arms of the ferrite switch must be at least $25 \mathrm{db}$ (roughly a factor of 300 ).

Higher frequency microwave signals can be used to study higher electron densities, but this requires either that the plasma tube radius be smaller because the waveguide dimensions are smaller, or that microwave radiation be propagated through a free-space plasma, in which case microwave horns (waveguide-to-free-space transitions) must be employed.

Analogous measurements for higher electron densities have been developed at infrared $^{3}$ and optical frequencies. 4

\subsection{MICROWAVE CAVITY MEASUREMENT OF ELECTRON DENSITY AND COLLISION FREQUENCY}

a. Relation between Cavity Resonance Parameters and the Electron Density and Collision Frequency

The use of resonant microwave cavities $^{2}$ for electron density measurements has been thoroughly discussed. ${ }^{5-7}$ The resonant frequency $f_{o}$ and the quality factor $Q$ are the two quantities characterizing a particular cavity resonance. The resonant frequency is a function of the cavity dimensions and the configuration or "mode" of the electromagnetic fields associated with the resonance. within the cavity. The $Q$ of a particular resonance is $f_{o} / \Delta f$, where $\Delta f$ is the full width at half-maximum of the power transmission curve of the cavity plotted as a function of frequency. Expressed in terms of the 
cavity parameters, $Q$ is equal to $2 \pi$ times the ratio of energy of the electromagnetic field within the cavity divided by the energy lost per second, because of resistive losses arising from the currents induced in the cavity walls and in any medium within the cavity and coupling of energy out of the cavity into the external load. The unloaded $Q$ of a cavity resonance, $Q_{0}$, depends only on the losses at the cavity walls and the resonance mode. Typical values of $Q_{0}$ range from $10^{4}$ to $3 \times 10^{4}$ for brass cavity walls, and are approximately a factor of two larger for silver-plated cavity walls.

A plasma placed inside a microwave cavity introduces a change in $f_{0}$ and $Q$. The effects of the induced electron current $\vec{J}=n(-e) \vec{v}$ (Eq. 3b) are conveniently included in the plasma index of refraction, $\mu$, which, from Eq. 8, is seen to be given by

$$
\mu^{2}=\left(1-\frac{\omega_{\mathrm{p}}^{2}}{v_{\mathrm{m}}^{2}+\omega^{2}}\left[1+\frac{i v_{\mathrm{m}}}{\omega}\right]\right),
$$

where the appropriate average of the collision frequency $v_{\mathrm{m}}$ over the electron velocity distribution may be included by the means described following Eq. 11.

The change of $Q$ of a resonance of a cavity into which a medium of index of refraction, $\mu$, is introduced is given by

$$
\begin{aligned}
\Delta\left(\frac{l}{\mathrm{Q}}\right) & =-\frac{\int\left[\mu^{2}\right]_{\mathrm{I}} \overrightarrow{\mathrm{E}}_{\mathrm{O}} \cdot \overrightarrow{\mathrm{E}}_{\mathrm{O}} \mathrm{dV}}{\int \overrightarrow{\mathrm{E}}_{\mathrm{O}} \cdot \overrightarrow{\mathrm{E}}_{\mathrm{O}} \mathrm{dV}} \\
& =\left(\frac{{ }^{{ }_{\mathrm{m}}} / \omega}{\omega^{2}+\nu_{\mathrm{m}}^{2}} \frac{\int \omega_{\mathrm{p}}^{2} \overrightarrow{\mathrm{E}}_{\mathrm{o}} \cdot \overrightarrow{\mathrm{E}}_{\mathrm{o}} \mathrm{dV}}{\int \overrightarrow{\mathrm{E}}_{\mathrm{O}} \cdot \overrightarrow{\mathrm{E}}_{\mathrm{O}} \mathrm{dV}}\right)_{\text {for a plasma }}
\end{aligned}
$$

and the fractional shift in resonant frequency is

$$
\begin{aligned}
\frac{\Delta f}{f_{0}} & =\frac{1}{2} \frac{\int\left(\left[\mu^{2}\right]_{R}-1\right) \vec{E}_{o} \cdot \vec{E}_{o} d V}{\int \vec{E}_{o} \cdot \vec{E}_{o} d V} \\
& =\left(-\frac{1}{2} \frac{1}{\omega^{2}+\nu^{2}} \frac{\int \omega_{p}^{2} \vec{E}_{o} \cdot \vec{E}_{o} d V}{\int \vec{E}_{o} \cdot \vec{E}_{o} d V}\right)_{\text {for a plasma }}
\end{aligned}
$$

where the subscripts I and $R$ refer to the imaginary and real parts of $\mu^{2}$, respectively, $\overrightarrow{\mathrm{E}}_{\mathrm{O}}$ is the electric field of the cavity mode corresponding to $f_{0}$ that exists in the absence of the medium, and the integration extends over the cavity volume. Because the unperturbed field, $\vec{E}_{O}$, is used in this expression, it constitutes a first-order perturbation calculation of the frequency-shift, and therefore is valid only for plasma sufficiently 
tenuous that the fields are not greatly changed by the plasma so that $\Delta f / f_{0} \ll 1$. For a plasma, it is seen from Eqs. 17 and 18 that

$$
\Delta \frac{1}{\mathrm{Q}}=-2 \frac{{ }^{\nu} \mathrm{m}}{\omega} \frac{\Delta \mathrm{f}}{\mathrm{f}_{\mathrm{o}}}
$$

The $Q$ of a plasma-filled cavity is given by

$$
\frac{1}{\mathrm{Q}}=\frac{1}{\mathrm{Q}_{\mathrm{e}}}+\Delta\left(\frac{1}{\mathrm{Q}}\right)
$$

where $\mathrm{Q}_{\mathrm{e}}$ is the empty-cavity $\mathrm{Q}$. It is seen from Eqs. 18 and 19 that a measurement of the resonance width and shift will yield the electron density and the collision frequency. Furthermore, from Eq. $18 \mathrm{~b}$, it is seen that if $\nu_{\mathrm{m}}$ is known or negligibly small, the electron density can be determined from $\Delta f / f_{0}$ alone.

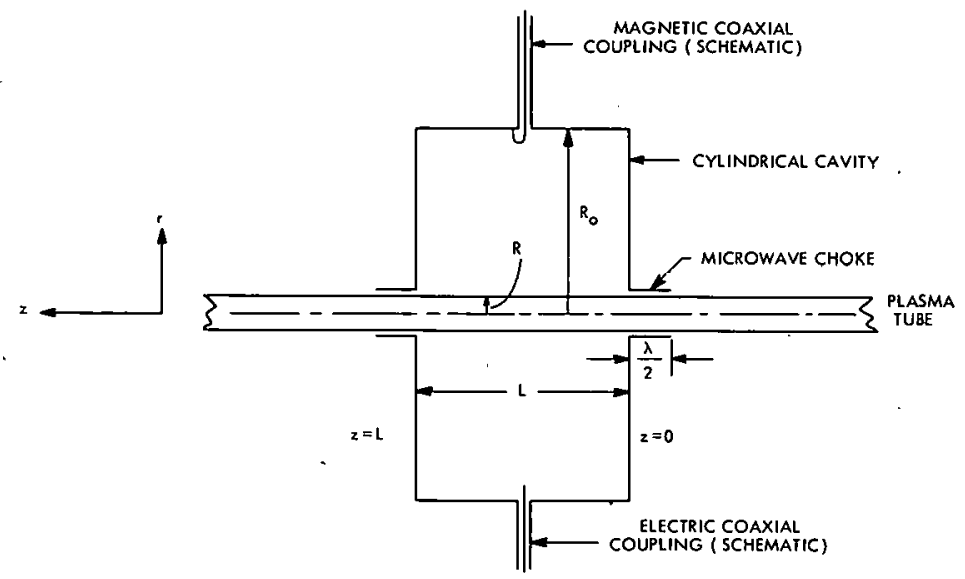

Fig. 3. Diagram showing typical plasma tube and microwave cavity configurations for microwave cavity study of plasma.

A typical microwave density measurement of electron density might involve the plasma and cavity arrangement shown in Fig. 3. As in the case of the microwave interferometer, the plasma tube should be made of thin-walled quartz so as to minimize perturbation of the cavity resonance. The effect of the tube wall on the frequency shift can be included in Eq. 18 but, for experimental conditions in which the first-order perturbation expression is valid, this introduces a constant shift in frequency and does not change the proportionality factor between $\Delta \omega$ and the electron density $\left(\omega_{p}^{2}\right)$. Another effect is that resulting from the holes in the cavity face because of the plasma tube. This effect can be accounted for. ${ }^{8}$ For a ratio $L / R<4$ (see Fig. 3) the error introduced is less than 10 per cent.

The plasma radius $R$ should be between $0.1 R_{0}$ and $0.2 R_{0}$ for satisfactory results. 
Coaxial coupling into and out of the cavity is accomplished, as shown schematically on Fig. 3, by using a loop for magnetic coupling which has its plane oriented perpendicular to the cavity magnetic field at the loop position, or a probe for electric coupling which is oriented parallel to the cavity electric field at the probe position. Waveguide-tocavity $^{2}$ coupling are also possible.

The following discussion is specialized to the geometry of Fig. 3. It is convenient to introduce a dimensionless form factor

$$
\eta=\frac{-\int \frac{{ }^{n}(x, y)}{n_{o}} \vec{E}_{o} \cdot \vec{E}_{o} d V}{\int \vec{E}_{o} \cdot \vec{E}_{o} d V},
$$

where $n_{0}$ is the maximum electron density, so that we may now write

$$
\frac{\Delta f}{f_{o}}=-\frac{1}{2} \frac{\omega_{p o}^{2}}{\omega^{2}+v_{m}^{2}} \eta
$$

and

$$
\Delta\left(\frac{1}{Q}\right)=\frac{\omega_{\text {po }}^{2}}{\omega^{2}+v_{m}^{2}} \frac{v_{m}}{\omega} \eta .
$$

The form factor $\eta$ then depends on the magnitude of the cavity electric field for the cavity mode that is being considered in the region of the plasma.

Biondi and Brown ${ }^{5}$ found that with the type of arrangement in Fig. 3 low electron densities could be measured by using the $\mathrm{TM}_{010}$ mode of cavity. This "transverse magnetic" mode has an electric field only in the $z$-direction (parallel to the cavity axis), $\mathrm{E}_{\mathrm{z}}=$ $E_{z O} J_{0}\left(\frac{2.4 r}{R_{0}}\right)$, where $J_{0}$ is the Bessel function of zero order, and $J_{0}(2.4)=0$. The magnetic field is only in the $\theta$ (azimuthal) direction, and hence the magnetic coaxial-coupling loop, as shown in Fig. 3, is oriented properly for coupling to this mode. Because the electric field is large near the cavity axis where the plasma is situated, this mode is

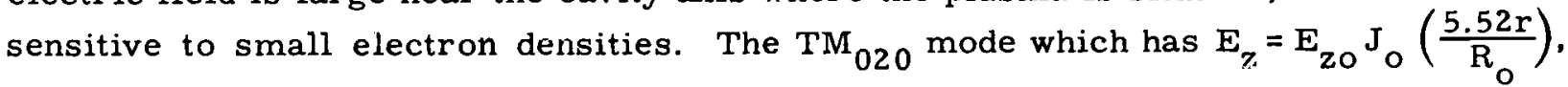
where $J_{0}(5.52)=0$, is also useful for measuring low electron densities, and can be extended to slightly higher electron densities than the $\mathrm{TM}_{010}$ because its resonant frequency is higher.

In Fig. 4 are plotted values of $\eta$ for these two modes as a function of plasma radius, $R$, divided by the cavity radius, $R_{0}$. The $\eta$-values are given for two types of electron spatial distributions within the plasma tube: $n=n_{0} J_{0}\left(\frac{2.4 r}{R}\right)$ which occurs at lower pressures when electron loss is due to diffusion; and $n=n_{0}=$ constant which occurs at higher pressures or electron densities for which electron loss is due to attachment or 


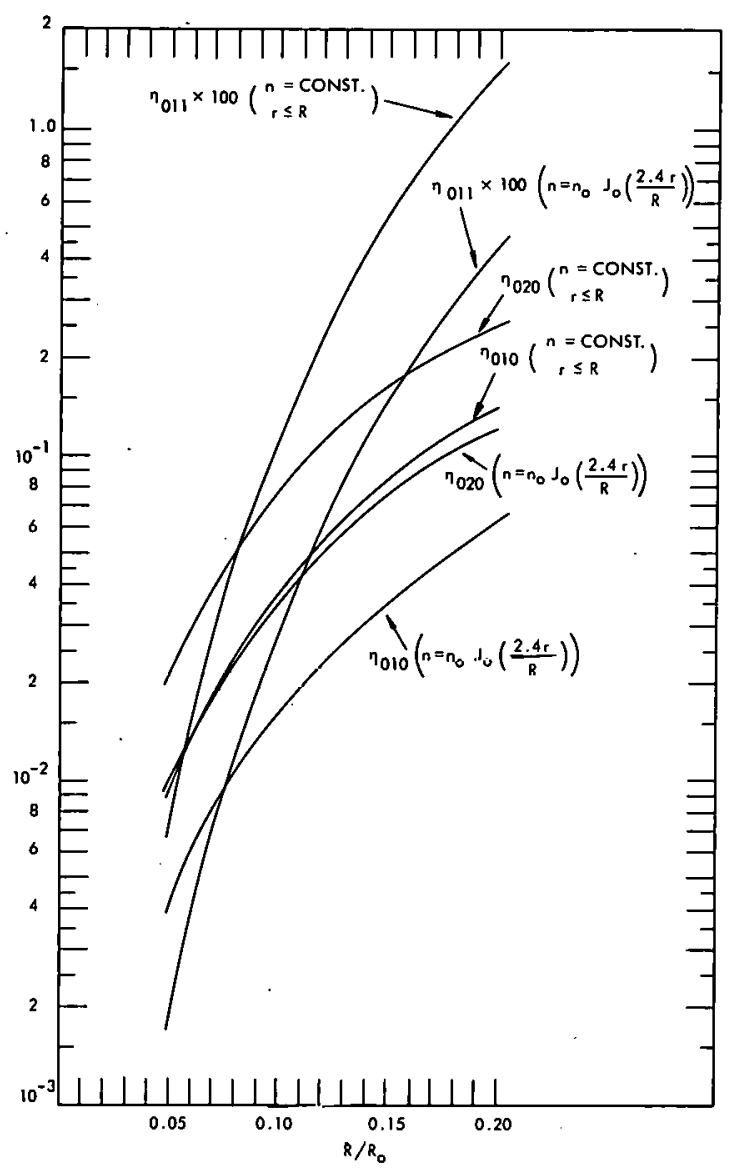

Fig. 4. Semilogarithmic plots of the form factor $\eta$ as a function of plasma radius divided by cavity radius for $\mathrm{TE}_{011}, \mathrm{TM}_{020}$, and $\mathrm{TM}_{010}$ cavity modes. The electron density is assumed to be distributed according to $n / n_{0}=J_{0}(2.4 r / R)$ for one case, and to be constant oyer the tube radius for the other case.

recombination. The perturbation theory. gives good agreement with the exact theory for these two modes, ${ }^{7,9}$ roughly up to a density corresponding to

$$
\frac{\omega_{p o}^{2}}{\omega^{2}+v_{m}^{2}}=1 .
$$

When using the $\mathrm{TM}_{020}$ mode for electron-density measurement a ratio of $2 \mathrm{R}_{\mathrm{O}} / \mathrm{L}=1.8$ causes all other cavity-mode frequencies to be sufficiently removed from the $\mathrm{TM}_{020}$ resonant frequency. Alternatively, mode filters may be incorporated into the cavity to suppress the undesirable modes. Wire mesh placed within the cavity will suppress modes whose electric vectors are parallel to the wire. As will be discussed in connection with the $\mathrm{TE}_{011}$ mode, slits in the cavity wall suppress modes whose magnetic vector at the 
wall is parallel to the slits.

For the measurement of higher electron densities ${ }^{10}$ the transverse electric mode, $\mathrm{TE}_{011}$, can be used. The electric field for this mode is $\mathrm{E}_{\theta}=\mathrm{E}_{0} \mathrm{~J}_{1}\left(\frac{3.83 \mathrm{r}}{\mathrm{R}}\right) \sin \frac{\pi \mathrm{z}}{\mathrm{L}}$, where $J_{1}(0)=J_{1}(3.83)=0$. Because this mode has a small electric field in the plasma region, and the electric field is everywhere perpendicular to the electron density gradients ${ }^{9}$ (assumed to be only in the radial direction), the first-order perturbation expression has been found to be in good agreement with the exact theory up to values of the electron density corresponding to

$$
\frac{\omega_{\mathrm{po}}^{2}}{\omega^{2}+v_{\mathrm{m}}^{2}}=10
$$

The coupling to this mode is achieved by rotating the magnetic loop of Fig. $390^{\circ}$ so that it is parallel to the end walls of the cavity. This mode is degenerate with the TM 111 mode which generally invalidates the perturbation theory. The presence of the quartz plasma tube acts to remove this degeneracy, however. To properly suppress the TM 111 mode (as well as all other TM modes), azimuthal slots should be cut in the cylindrical wall of the cavity.

The minimum electron density that is measurable is limited by the width of the cavtity resonance. That is, the higher the cavity $Q$ the smaller is the minimum measurable electron density. The minimum measurable frequency shift will be approximately

$$
-\left(\frac{\Delta f}{f_{o}}\right)_{\min } \approx \frac{1}{2}\left(\frac{1}{Q}\right)=\frac{1}{2}\left(\frac{1}{Q_{e}}+\Delta\left(\frac{1}{Q}\right)_{\text {plasma }}\right) \text {. }
$$

Generally, in the low electron density limit. $1 / Q \approx 1 / Q_{e}$. In this case, the smallest electron densities are measured when the coupling of the cavity to the external circuit is made as weak as possible so as to maximize the loaded $Q$ of the cavity. In Table 1 are given the minimum and maximum measurable electron densities for the three cavity modes, where the maximum density is calculated by using either Eqs. 23 or 24, under the assumption that $v_{\mathrm{m}} / \omega \ll 1$, and the minimum density is calculated by using Eq. 25, under the assumption that $Q=10^{4}$. The cavity is assumed to have a radius $R_{0}=6.25 \mathrm{~cm}$, a length of $10 \mathrm{~cm}$, and the plasma radius is taken as $R=1 \mathrm{~cm}$ with the electron density given by $n=n_{0} J_{0}\left(\frac{2.4 r}{R}\right)$. By silver - plating the cavity walls and taking careful measurements, the minimum measurable density given in Table 1 can be reduced an order of magnitude further.

At higher pressures at which $v_{\mathrm{m}}$ becomes comparable with $\omega$, accurate measurement of the cavity frequency shift becomes impossible. At higher pressures, $\frac{1}{Q}=\frac{1}{Q_{e}}+\Delta\left(\frac{1}{Q}\right) \approx$ $\Delta\left(\frac{1}{Q}\right)$. A measurable frequency shift, according to Eq. 25 , must satisfy the inequality $-\left(\frac{\Delta \mathrm{f}}{\mathrm{f}_{\mathrm{o}}}\right) \geqslant \frac{1}{2} \frac{1}{\mathrm{Q}} \approx \frac{1}{2} \Delta\left(\frac{1}{\mathrm{Q}}\right)$. But, from Eq. 19, $\left(\Delta \frac{1}{\mathrm{Q}}\right)=-2 \frac{{ }^{\nu} \mathrm{m}}{\omega} \frac{\Delta \mathrm{f}}{\mathrm{f}_{\mathrm{o}}}$ so that the inequality 
Table 1. Tabulation of minimum and maximum measurable electron densities for $\mathrm{TM}_{010}, \mathrm{TM}_{020}$, and $\mathrm{TE}_{011}$ modes of a cylindrical cavity with $Q_{0}=10^{4}, R_{o}=6.25 \mathrm{~cm}, L=10 \mathrm{~cm}$, and plasma radius $R=1 \mathrm{~cm}$, where the electrons are distributed according to $n=n_{0} J_{0}\left(\frac{2.4 r}{R}\right)$.

\begin{tabular}{|l|c|c|c|c|c|c|}
\hline Mode & $f_{0}(\mathrm{kmc})$ & $\lambda_{0}(\mathrm{~cm})$ & $\mathrm{n}_{\mathrm{o} \min }\left(\mathrm{cm}^{-3)}\right.$ & $\left(\frac{\Delta f}{f_{0}}\right)_{\min }$ & $\mathrm{n}_{\mathrm{omax}}\left(\mathrm{cm}^{-3}\right)$ & $\left(\frac{\Delta f}{f_{0}}\right)$ \\
\hline $\mathrm{TM}_{010}$ & 1.835 & 16.35 & $1 \times 10^{8}$ & $1 / 2 \times 10^{-4}$ & $4.2 \times 10^{10}$ & $2 \times 10^{-2}$ \\
\hline $\mathrm{TM}_{020}$ & 4.215 & 7.12 & $3 \times 10^{8}$ & $1 / 2 \times 10^{-4}$ & $2.2 \times 10^{11}$ & $3.8 \times 10^{-2}$ \\
\hline $\mathrm{TE}_{011}$ & 3.290 & 9.13 & $7 \times 10^{9}$ & $1 / 2 \times 10^{-4}$ & $1.3 \times 10^{12}$ & $9.5 \times 10^{-3}$ \\
\hline
\end{tabular}

Table 2. Tabulation of the minimum and maximum measurable electron densities in a cylindrical cavity.with $R_{0}=6.25 \mathrm{~cm}$ and $L=10 \mathrm{~cm}$, where $R / R_{0}=0.1$ and the electron density is assumed constant for $r>R$. Calculations were made for electrons in helium gas at a pressure of 1 atm

\begin{tabular}{|l|c|c|c|c|c|c|}
\hline Mode & $f_{0}(\mathrm{kmc})$ & $\lambda_{0}(\mathrm{~cm})$ & $n_{0 \min }\left(\mathrm{cm}^{-3}\right)$ & $\left(\Delta \frac{1}{\mathrm{Q}}\right)_{\min }$ & $\mathrm{n}_{\mathrm{omax}}\left(\mathrm{cm}^{-3}\right)$ & $\left(\Delta \frac{1}{\mathrm{Q}}\right)_{\max }$ \\
\hline $\mathrm{TM}_{010}$ & 1.835 & 16.35 & $1.8 \times 10^{10}$ & $10^{-4}$ & $6.7 \times 10^{12}$ & $\eta_{010}=3.7 \times 10^{-2}$ \\
\hline $\mathrm{TM}_{020}$ & 4.215 & 7.12 & $2.0 \times 10^{10}$ & $10^{-4}$ & $1.5 \times 10^{13}$ & $\eta_{020}=7.8 \times 10^{-2}$ \\
\hline $\mathrm{TE}_{011}$ & 3.290 & 9.13 & $1.1 \times 10^{12}$ & $10^{-4}$ & $1.2 \times 10^{14}$ & $1.0 \eta_{011}=1.1 \times 10^{-2}$ \\
\hline
\end{tabular}


reduces to $-\frac{\Delta f}{f_{o}} \geqslant-\frac{\nu_{m}}{\omega} \frac{\Delta f}{f_{o}}$, thereby showing that the frequency shift method is not useful unless $v_{\mathrm{m}}<\omega$. In such cases as this measurement of the cavity $Q$ is necessary, which, when combined with an independently determined value of $v_{m}$ ' is sufficient to determine the electron density. For example, taking helium at 1 atm pressure, as we did above, and using the resonant cavity presented in Table 1, we may compute the ranges of measurable electron densities for the three cavity modes from a measurement of $\Delta\left(\frac{1}{Q}\right)$. The minimum measurable electron density will be approximately determined by the condition

$$
\left(\Delta \frac{1}{\mathrm{Q}}\right)_{\min }=\frac{1}{\mathrm{Q}_{\mathrm{O}}}
$$

and Eq. 22b, and the maximum measurable electron density by conditions analogous to Eqs. 23 and 24.

$$
\frac{v_{m}}{\omega} \frac{\left(\omega_{p o}^{2}\right)_{\max }}{v_{m}^{2}+\omega^{2}}=1
$$

for the $\mathrm{TM}_{010}$ and $\mathrm{TM}_{020}$ modes, and

$$
\frac{\nu_{\mathrm{m}}}{\omega} \frac{\left(\omega_{\mathrm{po}}^{2}\right)_{\max }}{\nu_{\mathrm{m}}^{2}+\omega^{2}}=10
$$

for the $\mathrm{TE}_{011}$ mode. These last conditions have not been justified by a comparison with the exact theory as were Eqs. 23 and 24, but are of the proper order of magnitude. Table 2 gives a tabulation of these results, under the assumptions that $Q_{0}=10^{4}$ and the electron density is distributed uniformly across the plasma. The plasma radius is assumed to be $R=0.625 \mathrm{~cm}$ so that $R / R_{0}=0.1$. It is seen that the range of measurable electron densities in Table 2 relative to those in Table 1 is shifted upward by roughly a factor of the ratio $\nu_{\mathrm{m}} / \omega$ evaluated at the high pressure.

This method for measuring electron density depends on a knowledge of $v_{\mathrm{m}}$ by some independent means, and, if $v_{\mathrm{m}}$ depends on electron velocity, the electron temperature must be known, too, so that the proper average over the electron velocity distribution may be computed.

b. Experimental Methods for Measurement of $\Delta f / f_{0}$ and $\Delta(1 / Q)$

of a Resonant Cavity

In the following discussion we shall describe the experimental methods for measurement of $\Delta f / f_{0}$ and $\Delta(l / Q)$. The measurement of fractional shift in resonant frequency, 
$\Delta f / f_{o}$, is the more straightforward of the two measurements, and is a useful diagnostic tool at lower gas pressures. The measurement principle involves measuring the cavity resonant frequency with and without the plasma, which is done by determining the frequency for which the power transmitted through the cavity is a maximum or the power reflected from the cavity back toward the signal generator is a minimum.

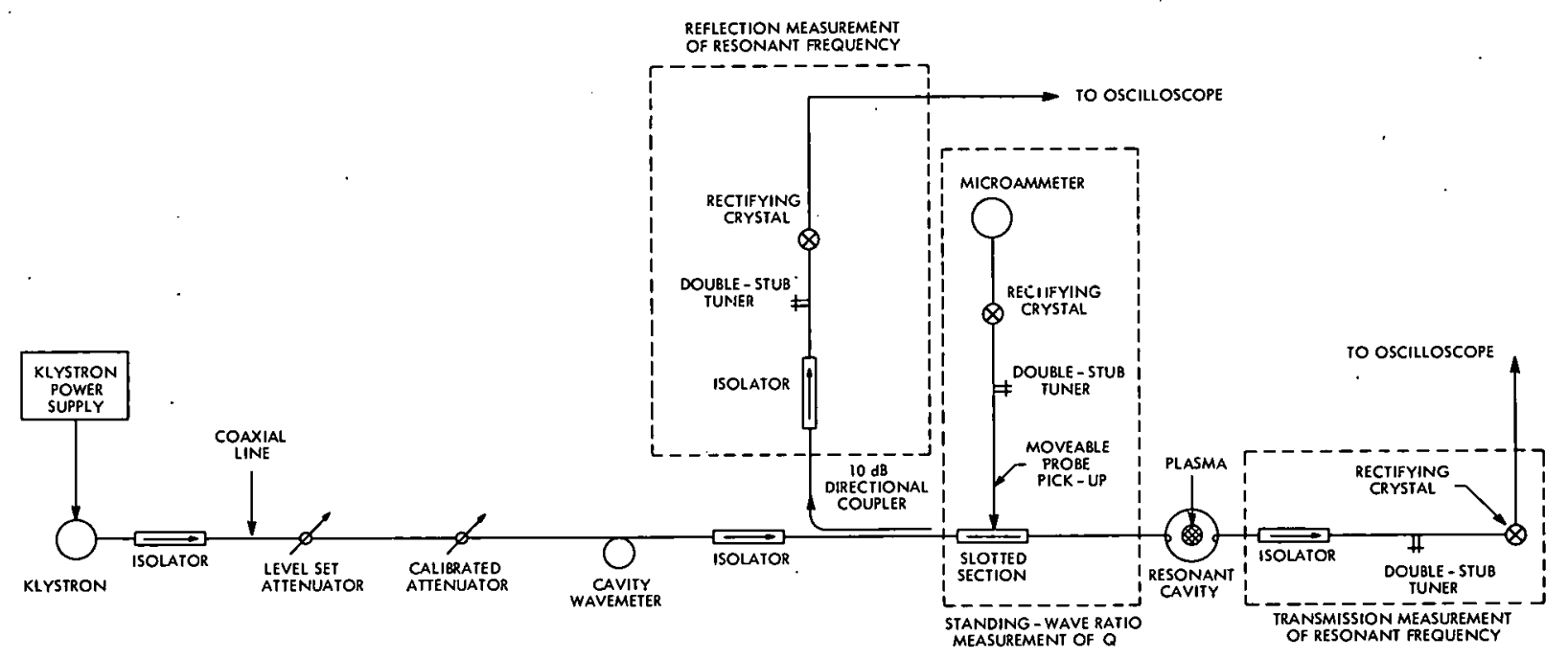

Fig. 5. Microwave resonant cavity circuit for. measurement of $Q$ and resonant frequency of a cavity resonance.

Figure 5 shows a typical coaxial-line microwave circuit suitable for making either a transmission or reflection measurement of the resonant frequency. The appropriate components for the two measurements are indicated in the diagram. It is important that isolators be employed in the input and output transmission lines to the cavity so that external-circuit reflections cannot perturb the cavity resonance. The reflection, measurement has the advantage that it requires only one coupling into the cavity, whereas the transmission measurement has the advantage that it receives a signal only in the immediate neighborhood of the resonance and, as a result, is slightly more sensitive. Both types of measurement on either a steady-state or transient plasma are conveniently carried out by modulating the klystron reflector voltage which so modulates the klystron frequency that the frequency is swept across the cavity resonance. The oscilloscope trace, which should be triggered synchronously with the klystron modulation will display a dip or rise as the klystron frequency passes through the cavity resonance. The frequency of this resonance is determined by the cavity wavemeter (Fig. 5) whose absorption frequency has been calibrated and is variable. The absorption of the wavemeter will also be displayed on the oscilloscope trace and may be moved by adjusting the wavemeter until it is coincident with the cavity resonance, at which point the two frequencies are equal. If this technique is applied to a repetitively pulsed plasma, the klystron modulation 
must also be synchronized with the plasma pulsing rate.

Rose and Brown ${ }^{6}$ discuss in some detail the theory and method of measurement of $\left(\Delta \frac{1}{Q}\right)$ defined in Eq. 18a through measurement of the standing-wave ratio in the transmission-line coupling into the cavity. They discuss the measurement in terms of the equivalent conductance, $g_{d}$, of the plasma or discharge, which is

$$
g_{d}=\beta \Delta \frac{1}{Q}
$$

where $\beta$ is the coupling coefficient between the transmission line and the cavity, which must also be determined. The method for measurement of the standing-wave ratio and the means by which $\Delta \frac{l}{Q}$ is determined from the measurement will be described here, but the detailed theory will not be presented.

Standing-wave-ratio measurements should be made with the transmission measurement circuit shown in Fig. 5 disconnected to minimize complication. The klystron operates at a fixed frequency during each standing-wave-ratio measurement. In the transmission line which couples power into the cavity there will also be a wave reflected from the cavity traveling to the left. The combination of the incident and reflected waves. gives rise to a standing wave in the transmission line. Thus, as the movable probe pickup is moved along the slotted section, the microammeter deflection will vary between a maximum and minimum value. A quantitative measurement of the ratio of these two values is made by re-adjusting the calibrated power attenuator when the probe is at a position corresponding to a minimum so that the microammeter reading is the same as it was when the probe was at a position corresponding to a maximum. The difference in the power attenuator reading in decibels $(\mathrm{db})$ is the power standing-wave ratio in $\mathrm{db}, \mathrm{R}$. $R$ is related to the voltage standing-wave ratio, $R_{V}$ (not in $d b$ ), by the usual equation

$$
\mathrm{R}=20 \log _{10} \mathrm{R}_{\mathrm{V}}
$$

Such a measurement could be made on a repetitively pulsed plasma by replacing the
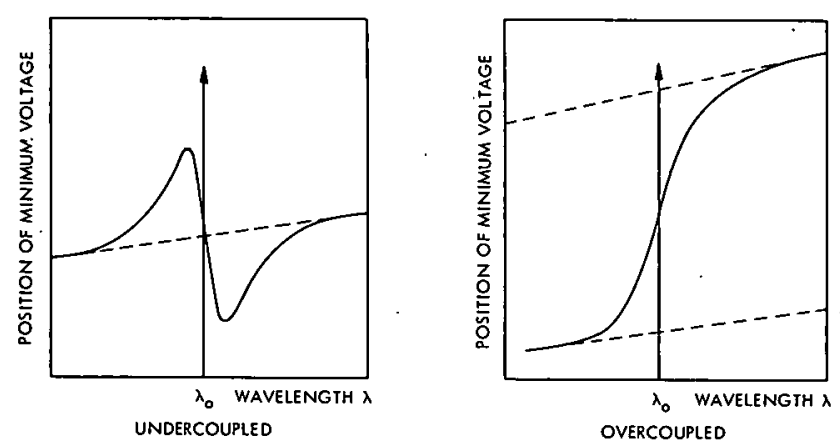

Fig: 6. The variation of position of a voltage minimum as the klystron frequency is varied across the cavity resonance. Slope of the dotted lines is due to the change in the wavelength in the transmission line. 
microammeter with an oscilloscope. Furthermore, by pulsing the klystron only for a short time during the plasma cycle at the time when the measurement was to be made, the accuracy of measurement could be increased. Equivalently, a marker generator could be used to indicate the time on the oscilloscope trace at which the measurement was being made.

One further measurement must be described. That is the determination of whether the cavity is undercoupled or overcoupled to the transmission line. The coupling is increased, for instance, by increasing the depth to which the coupling loop extends into the cavity volume. The distinction between undercoupling or overcoupling is made by varying the klystron frequency in stepwise fashion across the cavity resonance while adjusting the position of the probe pickup so that it remains at the position of a given voltage minimum. The positional behavior of a voltage minimum for the two cases is illustrated in Fig. 6.

The next step is to describe the particular standing-wave-ratio measurements that are to be made. The basic idea is that the fraction of incident power that is reflected from the cavity at resonance is a direct function of the conductance of the cavity and any medium within the cavity. Thus such a measurement made with and without the plasma yields sufficient information to determine $\left(\Delta \frac{1}{Q}\right)$, provided $\beta$ is known and losses in the coupling unit connecting transmission line and cavity can be corrected for.

The resonance curve of the cavity without the plasma must first be measured. Figure 7 shows a typical experimental resonance curve and on it are defined three power

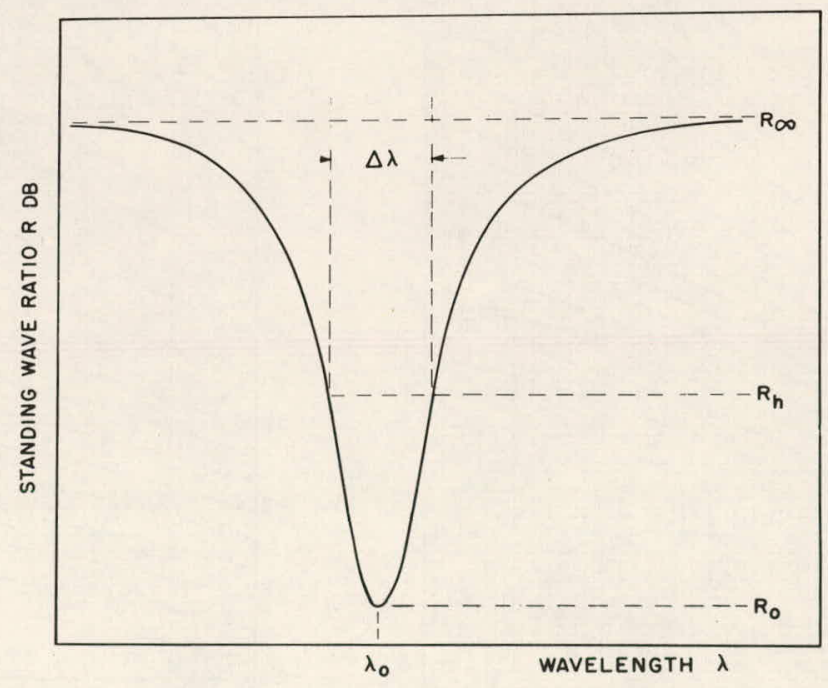

Fig. 7. Typical experimental resonance curve.

standing-wave-ratios that are to be measured: $R_{0}$, the ratio at resonance; $R_{\infty}$, the ratio very far from resonance (if losses in the coupling loop are negligible, $R_{\infty} \approx \infty$ ); and $R_{h}$, the ratio at the wavelength $\lambda=\lambda_{0} \pm \frac{\Delta \lambda}{2}$, where 

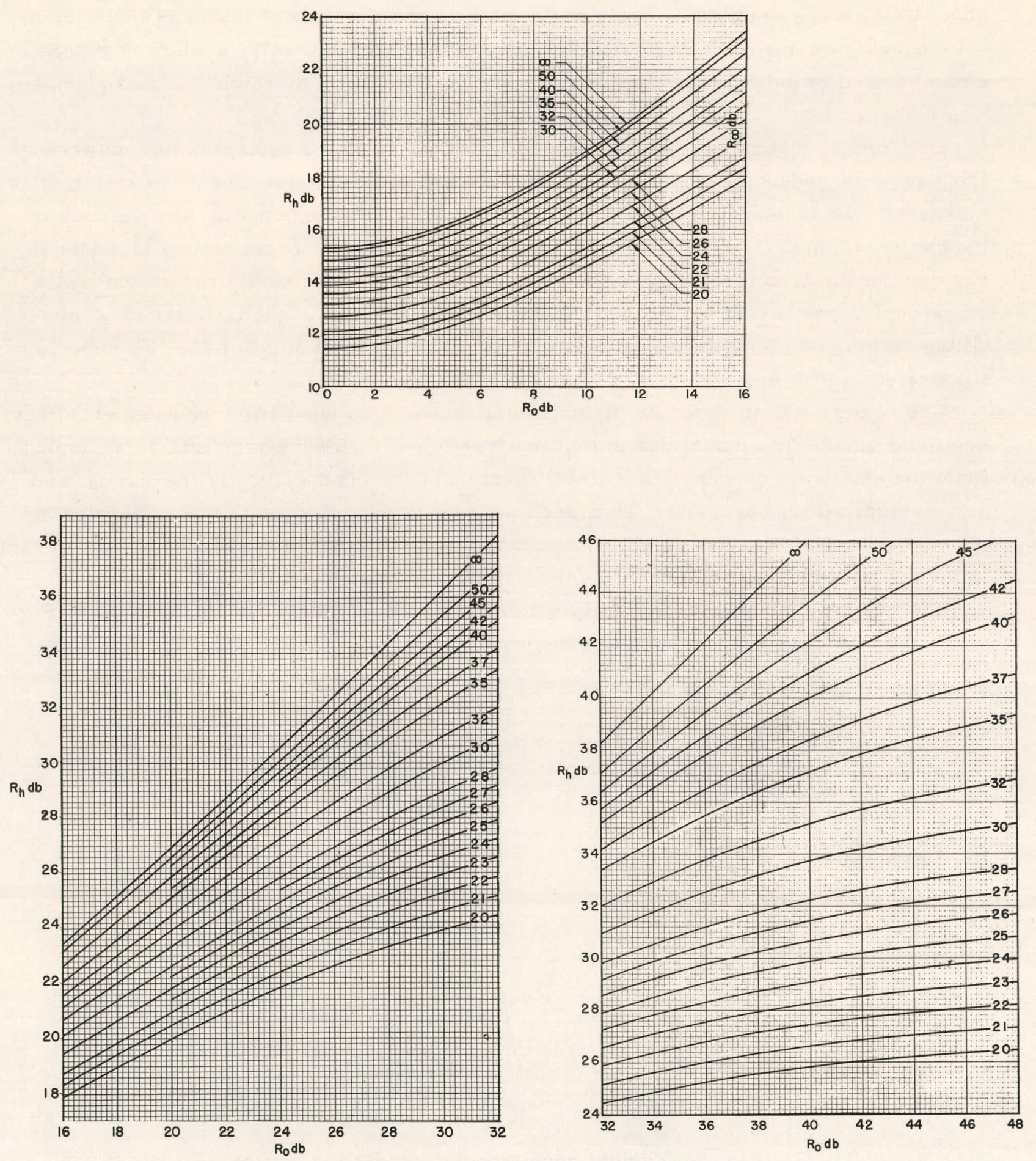

Fig. 8. Standing-wave ratio, $R_{h} d b$, as a function of standing-wave ratio on resonance. 


$$
Q_{L}=\frac{\lambda_{O}}{\Delta \lambda}=\frac{f_{o}}{\Delta f}
$$

and $Q_{L}$ is the loaded $Q$ of the cavity. The purpose of these three measurements is to determine the empty-cavity equivalent conductance, $g$, the coupling coefficient, $\beta$, and to correct for losses in the coupling circuit $\left(R_{\infty} \neq \infty\right)$.

The procedure is to measure $R_{0}$ and $R_{\infty}$, and at the same time determine whether the cavity is overcoupled or undercoupled. By convention, $R_{0}$ is taken to be negative if the cavity is undercoupled. That is, if $R_{0}$ were measured as $15 \mathrm{db}$ and the cavity were undercoupled, then it would be taken to be $-15 \mathrm{db}$. From Fig. 8, $R_{h}$ is then determined. With $R_{h}$ known, the frequencies at which $R_{h}$ occurs on the resonance curve can be determined experimentally, and thus $\Delta \lambda$ can be determined. From Eq. $30 \mathrm{Q}_{\mathrm{L}}$ is then determined. Referring to Fig. 9, it is then possible to determine the coupling coefficient $\beta$. From Fig. 10 the conductance of the cavity, $\mathrm{g}_{\mathrm{c}}^{\prime}$, is also determined. The plasma is now turned on and the standing-wave ratio at resonance is again measured. It is also necessary to determine whether the cavity is overcoupled or undercoupled for this case. Referring to Fig. 10, the total conductance of the cavity plus the plasma, $g_{T}^{\prime}=g_{c}^{\prime}+g_{d}$, is determined, and $g_{d}$ is found by subtracting $g_{c}^{\prime}$ from $g_{T}^{\prime}$. The coupling coefficient $\beta$ is unchanged by the presence of the plasma, so that $\left(\Delta \frac{1}{Q}\right)$ is determined immediately from
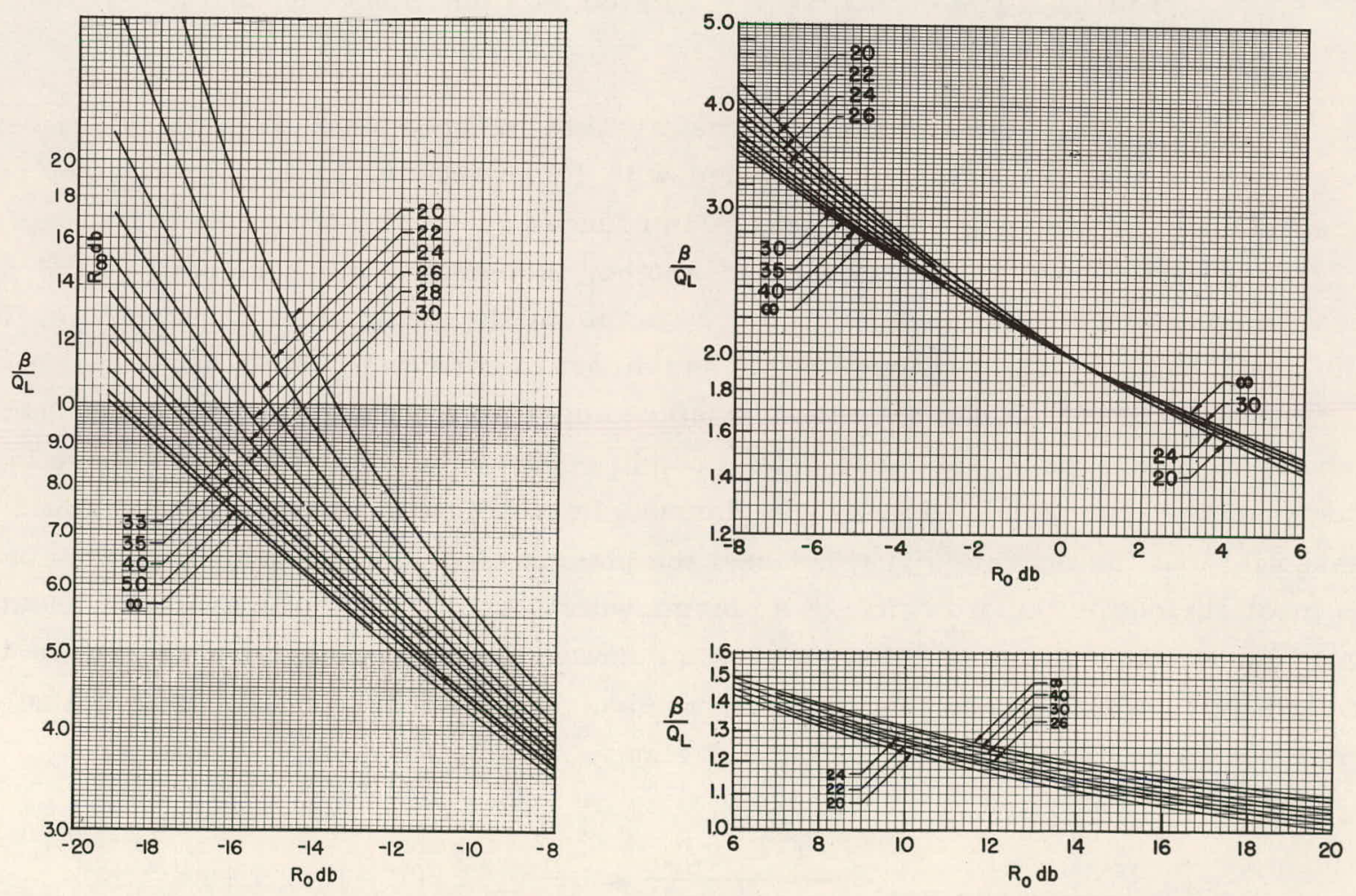

Fig. 9. Ratio of $\beta$ to loaded Q plotted as a function of standing-wave ratio on resonance. 

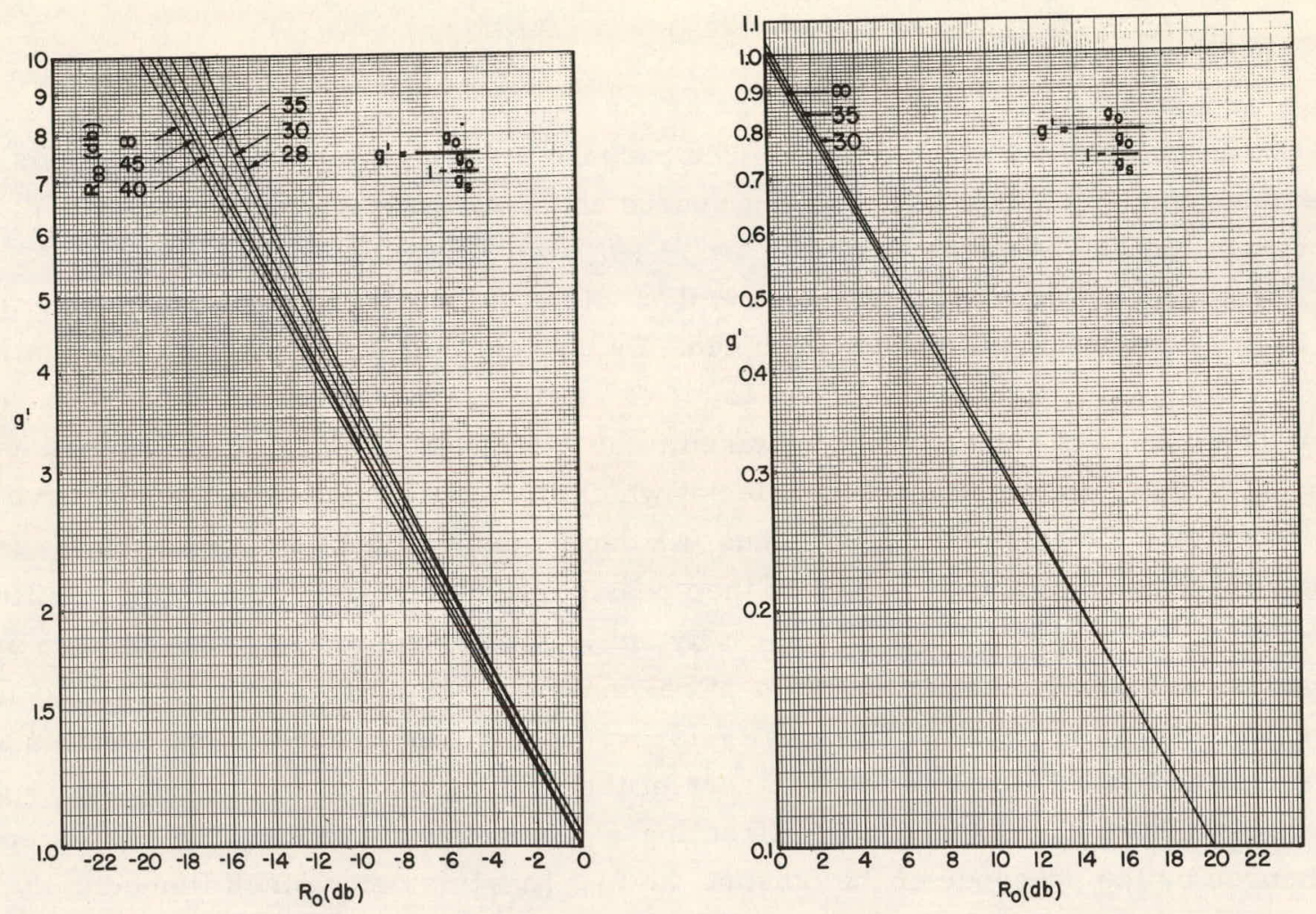

Fig. 10. The conductance $g^{\prime}$ plotted as a function of $R_{0}$ and $R_{\infty}$.

Eq. 28. The plasma tends to cause the cavity to be undercoupled. It is therefore best to begin with the empty cavity overcoupled with $R_{0} \approx+10 \mathrm{db}$, so that it will not be too greatly undercoupled when the plasma is introduced.

Gould and Brown ${ }^{11}$ have described another method for measurement of the discharge admittance which involves a more complicated experimental arrangement, but the measurement itself is more simple and direct to carry out.

In some cases ${ }^{12}$ it has been found useful to operate the cavity in two noninteracting modes simultaneously, one mode being used to produce the plasma by microwave breakdown and the other mode to study the plasma. In all microwave studies of plasma it is essential that the probing signal not heat the plasma electrons significantly. This problem is most serious in the afterglow of a plasma where the electron temperature is near the gas temperature. The condition that the microwave heating be negligible requires that rate of microwave energy absorption by an electron be small compared with the rate of energy loss by the electrons, because of elastic recoil collisions,

$$
\langle(-\mathrm{E}) \cdot \vec{v}\rangle_{\text {time average }} \cong \frac{\mathrm{e}^{2} \mathrm{E}_{\mathrm{o}}^{2} v_{\mathrm{m}}}{2 \mathrm{~m}\left(v_{\mathrm{m}}^{2}+\omega^{2}\right)} \ll \frac{2 \mathrm{~m}}{\mathrm{M}} v_{\mathrm{m}} \frac{3}{2} \mathrm{k}\left(\mathrm{T}_{\mathrm{e}}-\mathrm{T}_{\mathrm{g}}\right),
$$

where $\mathrm{m}$ is the electron mass, $\mathrm{M}$ is the gas-atom mass, $\mathrm{k}$ is Boltzmann's constant, and 
$\mathrm{T}_{\mathrm{e}}$ and $\mathrm{T}_{\mathrm{g}}$ are the electron and gas temperatures, respectively. For a rectangular waveguide of lateral dimensions $a$ and $b$, in which $P$ watts of power are propagating in: the lowest waveguide mode, the electric field at the waveguide center is ${ }^{2}$

$$
E_{\max }^{2}=\frac{P}{6.63 \times 10^{-4} \mathrm{ab}} \frac{\lambda g}{\lambda}
$$

where $E_{\max }$ is in volts/cm, and $\mathrm{a}$ and $\mathrm{b}$ are in $\mathrm{cm}$. For a resonant cavity, remembering the definition of the loaded $Q$ as $2 \pi$ times the ratio of stored energy to energy dissipated per cycle, we see that the power flow into the cavity per second must satisfy the relation

$$
\mathrm{P} \approx \frac{\text { Energy stored }}{\mathrm{Q}} \omega \approx \frac{\epsilon_{\mathrm{o}} \mathrm{E}_{\mathrm{oV} \omega}^{2}}{2 \mathrm{Q}},
$$

which can be conveniently rewritten as

$$
E_{O}^{2}=\frac{120 Q P \lambda}{V}
$$

with $E_{0}$ in volts $/ \mathrm{cm}, \lambda$ in $\mathrm{cm}$, and $V$ the cavity volume in $\mathrm{cm}^{3}$. In this equation $E_{o}$ represents a time-and-space average electric field within the cavity. More sensitive detection lechniques, which will be outlined below, can be employed if lower-level microwave signals need to be employed.

Substantial portions of the cavity walls may be removed ${ }^{13}$ without greatly disturbing the resonance properties, provided this removal does not act to suppress the mode according to the above-mentioned criteria. This allows greater freedom in the manner in which the plasma is introduced into the cavity.

\section{4 THERMAL RADIATION MEASUREMENT OF ELECTRON TEMPERATURE}

The emission of radiation from a perfectly absorbing and nonreflecting body into free space has a spectrum that is characteristic of the temperature of the body. In the long-wavelength limit where photon energies are much less than the thermal energy $\mathrm{kT}$, the specific intensity is

$$
I_{f}=\frac{k T}{\lambda^{2}}\left(\frac{\text { watts } \cdot \text { meter }^{-2}}{\left(\frac{\text { cycle }}{\text { sec }}\right) \cdot \text { steradian }}\right),
$$

where $I_{f}$ is the power emitted per frequency interval from unit area of the emitting sur face into unit solid angle, $\lambda$ is the wavelength, and $k \mathrm{~T}$ is in joules. This expression is derived by requiring that the spectrum be the same as that of electromagnetic radiation in thermal equilibrium in a three-dimensional reflecting enclosure.

The analogous one-dimensional problem for a perfectly absorbing nonreflecting body 
in a waveguide may be solved to obtain for the radiated power flow per frequency interval in one direction in the waveguide ${ }^{14}$

$$
P_{f}=k T \frac{\text { watts }}{(\text { cycle/sec) }}
$$

Comparing Eqs. 33 and 34, we see that Pf is equal to the power emitted from an area, $\lambda^{2}$, of a body in free space into 1 steradian of solid angle.

If the waveguide-contained radiating body is not completely absorbing, but absorbs only a fraction, A, of radiation propagated through it, reflects a fraction, $\Gamma$, and transmits a fraction, $t$, it can be shown that it emits an amount of power in this same propagation direction,

$$
P_{f}=A k T=(1-t-\Gamma) k T \text {. }
$$

This expression follows immediately if one requires that such a body emit as much energy per second as it absorbs when placed in a waveguide between two ideal radiators having its temperature.

At microwave frequencies the emission from a plasma is due only to the electrons to a good approximation. This radiation is due to the accelerations undergone by the electrons in collisions (Bremsstrahlung), or as they orbit in a magnetic field (cyclotron radiation). If the electrons have a Maxwellian distribution of velocities at a temperature $\mathrm{T}$, the microwave emission from the plasma will be characteristic of the electron temperature according to Eq. 35. Thus, a measurement of the plasma emission, transmission, and reflection can yield the electron temperature. In practice, if reflections

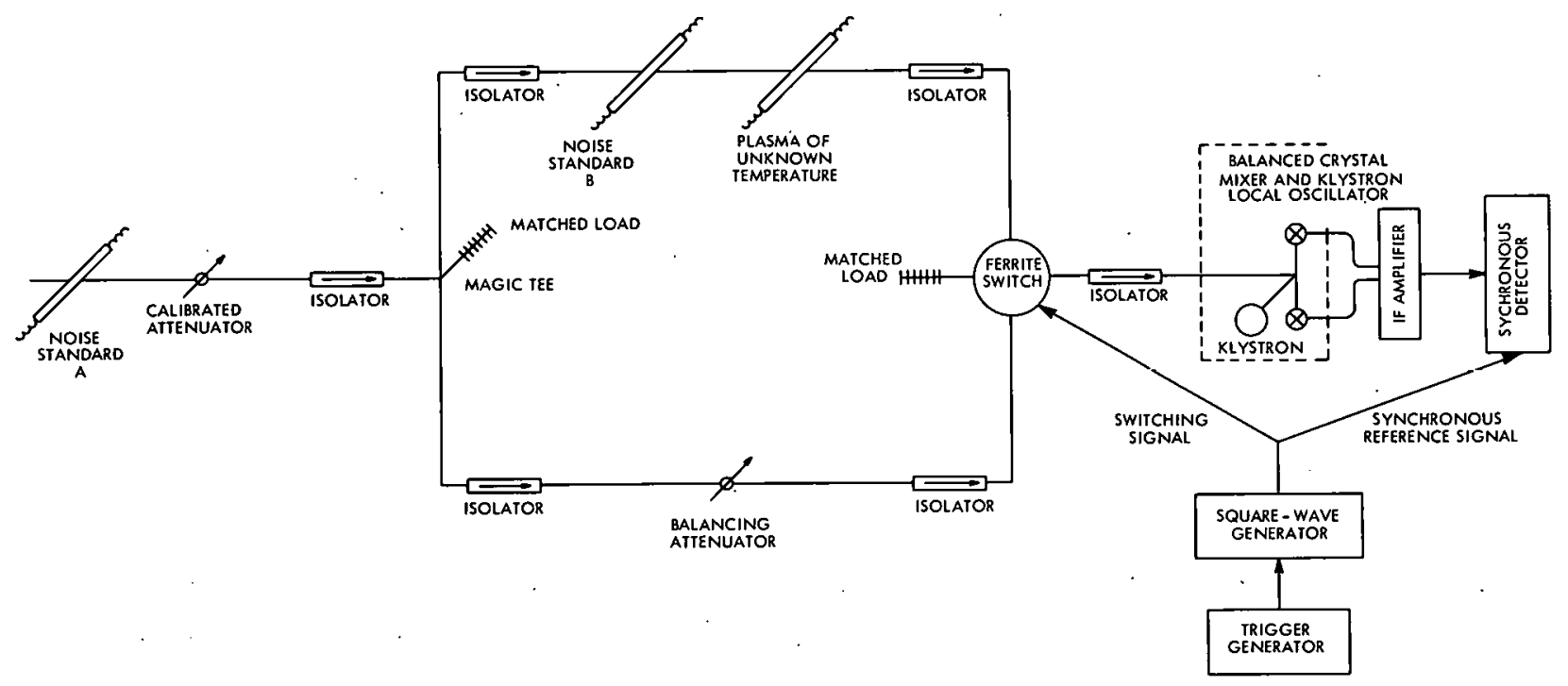

Fig. 11. Microwave bridge circuit, balanced crystal-mixer detector, and synchronous detector for measurement of electron temperature. 
are negligible, the temperature measurement can be accomplished in a single null measurement by using the microwave bridge circuit shown in Fig. 11. Many of the waveguide components have already been described. The noise standards are DC electrical gas discharges and, as with the plasma tube (see Fig. $1 \mathrm{a}$ and $\mathrm{lb}$ ), should be inserted through the broad face of the waveguide at an angle of from $6^{\circ}$ to $10^{\circ}$ with respect to the waveguide axis. The noise standards have been previously calibrated by using a heated matched load as a standard. Typical noise temperatures are $18,000^{\circ} \mathrm{K}$ for a neon discharge, and $12,000^{\circ} \mathrm{K}$ for an argon discharge. Noise standard $\mathrm{A}$ may be augmented by amplifying its radiation with a traveling-wave amplifier. The IF amplifier will have, typically, a 10-Mc bandwidth centered at $30 \mathrm{Mc}$ with a gain of $80 \mathrm{db}$. This amplifier selects that part of the radiation from the plasma and noise standards which is centered at $30 \mathrm{Mc}$ on either side of the klystron local-oscillator frequency. The switching signal to the ferrite switch is also used as a synchronous reference signal to the synchronous detector so that it amplifies only that component of the IF amplifier output having the proper envelope. The synchronous-detector signal is thus proportional to the difference between the signals of the two arms of the bridge so that a null measurement can be made.

The measurement of the steady-state electron temperatures proceeds as follows. With only noise standard $\mathrm{A}$ on, the bridge is balanced by adjusting the balancing attenuator. Noise standard $B$ is then turned on, and the calibrated attenuator adjusted until a balance is achieved. At this setting, the power from noise standard A traveling in either arm of the bridge is determined and corresponds to the temperature of noise standard B. Noise standard B is then turned off, and the plasma turned on. The calibrated attenuator is readjusted to again achieve a null. At this null, the power flow in the balance arm equals the power flow in the plasma arm in the frequency range that is being detected:

$$
k T_{S_{\text {eff }}}=t k T_{S_{\text {eff }}}+(1-t) k T_{p^{\prime}}
$$

where reflections are assumed to be negligible, $\mathrm{kT}_{\mathrm{S}_{\text {eff }}}$ is the effective power flow from the standard in the arms of the bridge as determined by the calibrated attenuator setting, $T_{p}$ is the plasma temperature, and $t$ is the plasma transmission.. Equation 36 requires that $T_{p}=T_{S_{e f f}}$ independent of $t$, so that $T_{p}$ is determined in a single measurement. When making temperature measurements near room temperature, the-radiation from the calibrated attenuator must also be included. For example, if $\mathrm{kT}_{\mathrm{S}_{\mathrm{O}}}$ is the power flow leaving noise standard $\mathrm{A}$ and the calibrated attenuator is set at an attenuation $\mathrm{A}$ and has a temperature $T_{R}$, then $k T_{S_{\text {eff }}}=(1-A) k T_{S_{0}}+A k T_{R}$. This type of experimental arrangement can detect temperature changes of $5^{\circ} \mathrm{K}$ in a perfect radiator. The sensitivity is reduced in proportion to $(1-t)$ if the body is not a perfect radiator.

If reflections from the plasma are important, at the null point $T_{p}=\frac{(1-t)}{(1-t-\Gamma)} T_{S_{e f f}}$, 
so that $T_{p}$ can still be determined if $\Gamma$, the power reflection coefficient, and $t$, the transmission coefficient, can be measured. $\Gamma$ can be determined from a standing-waveratio measurement, at the point between noise standard $B$ and the plasma. The trans mission $t$ can be determined by using this bridge to make an absorption measurement on the plasma, as described in section 1.2.

For this type of measurement to be effective, the plasma must not reflect too strongly (preferably not at all) and must absorb a sufficient fraction of power so that its emission is large enough. These criteria are especially important if the electron temperatures are only of the order of $1000^{\circ} \mathrm{K}$. The conditions that these criteria impose on the plasma parameters have been discussed in section 1.2.

An alternative method of microwave measurement of electron temperature is the reflection method. ${ }^{14}$ This technique allows the determination of the electron temperature in a plasma from a single measurement, even for cases in which reflections from the plasma boundaries are not negligible. In Fig. 12 such a microwave circuit is shown. Also shown are the electronic components for the time-resolved measurement of the

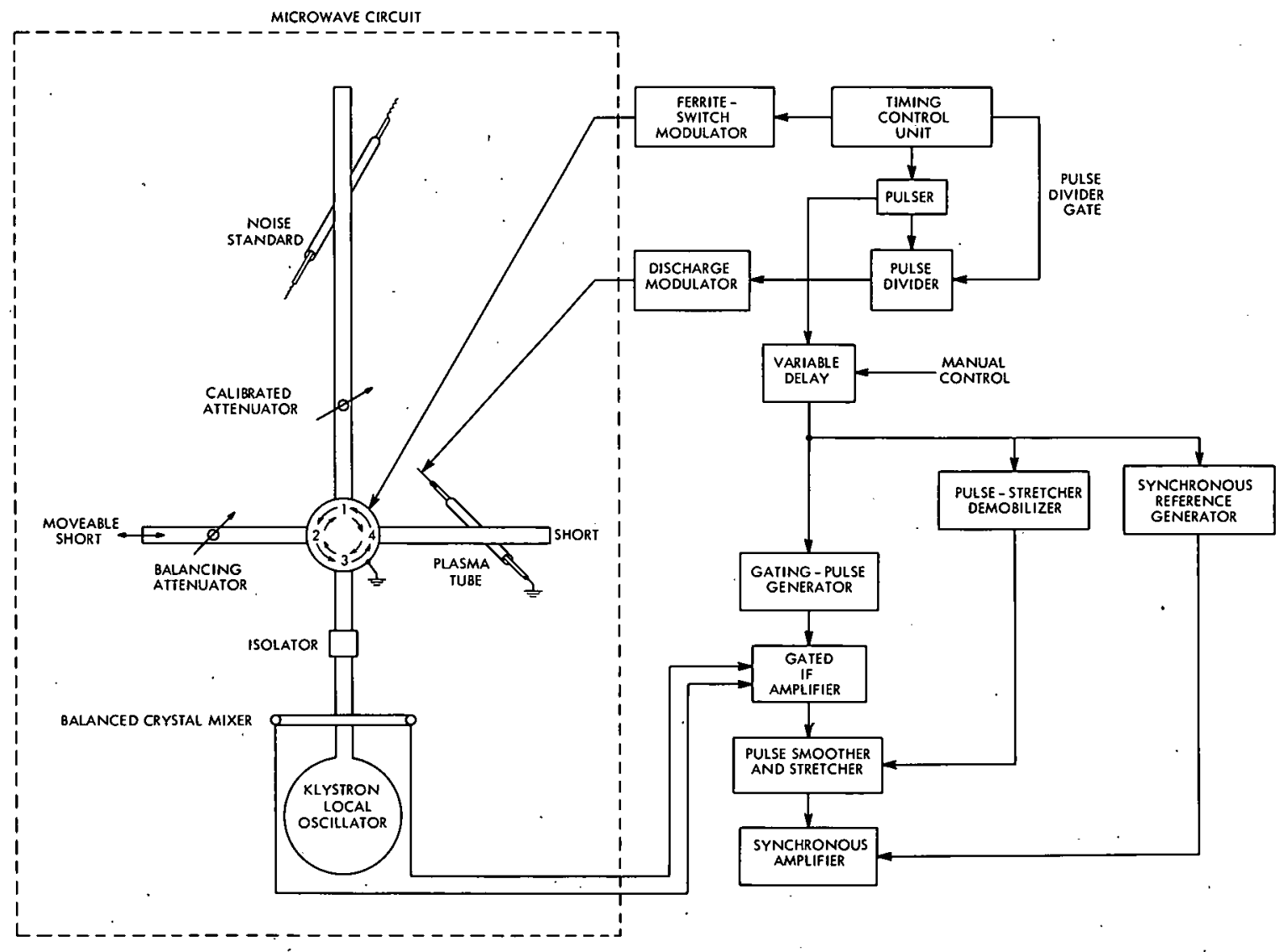

Fig. 12. Microwave circuit for reflection measurement of electron temperature and the electronic components that are necessary for measurement of transient temperature variations. 
transient electron temperature of a repetitively pulsed plasma.

To apply the reflection technique successfully, it is necessary, as in the bridgetemperature and bridge-attenuation measurements, to use a high-quality ferrite switch that has 25-30 db power isolation between its various ports and is well matched to the waveguide circuit. The criterion for good isolation between various ports is necessary because any signal from the noise standard arm that leaks into the receiver arm through one of the possible undesired paths adds coherently to the desired signal. For example, the resultant signal for $25-\mathrm{db}$ power isolation will still vary \pm 10 per cent as the relative phase of the two signals changes.

The two states of the ferrite switch are indicated by the circulating arrows in Fig. 12. The measurement is made by first balancing the circuit with the plasma off, and with the plasma on, and then adjusting the calibrated attenuator until a null is again achieved. At the null, the effective noise standard power, $\mathrm{kT}_{\mathrm{S}_{\mathrm{eff}}}$, which travels unattenuated to the receiver via the movable short arm, is equal to the sum of the plasma emitted power, $\epsilon k T_{p}$, plus that part of the standard power which is reflected from the plasma arm into the receiver, $\Gamma \mathrm{kT}_{\mathrm{S}_{\mathrm{eff}}}$, or in equation form,

$$
k \mathrm{~T}_{\mathrm{S}_{\mathrm{eff}}}=\Gamma \mathrm{kT} \mathrm{T}_{\mathrm{eff}}+\epsilon \mathrm{kT} \mathrm{p}^{\prime}
$$

where $\epsilon$ and $\Gamma$ are the power-emission and power-reflection coefficients of the plasma and reflecting-short configuration.

If in the plasma arm the only absorbing component is the plasma itself, the plasma electron temperature is equal to the effective noise standard temperature, $\mathrm{T}_{\mathrm{S}_{\text {eff }}}$, as determined by the calibrated attenuator. To see that this is the case, it is only

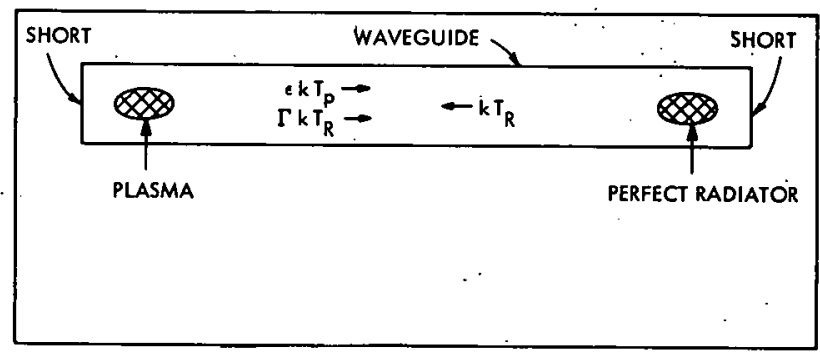

Fig. 13. Plasma and perfect radiator in waveguide. necessary to consider a plasma, waveguide, and perfect radiator in the configuration shown in Fig. 13. The plasma may be partly absorbing and partly reflecting. When the plasma and radiator are at the same temperature, the power flow to the left must equal the power flow to the right in each frequency interval (for $T_{p}=T_{R}$ ):

$$
\epsilon k T_{p}+\Gamma k T_{R}=k T_{R}
$$

which gives

$$
\epsilon=1-\Gamma
$$

for the emission coefficient of the plasma in terms of its reflection coefficient. Substituting Eq. 39 in Eq. 37, we find that $T_{p}=T_{S_{e f f}}$ independent of the plasma reflections. 
This method also allows greater freedom in the manner in which the plasma tube is mounted in the waveguide.

Also shown in Fig. 12 are the electronic components necessary for measurements of repetitive transient temperature behavior. The principle of the technique is to gate the IF amplifier so that it samples the radiation from each arm of the reflection arrangement for only a short time out of each cycle. The plasma is pulsed each time the ferrite switch is in the state that allows plasma radiation to reach the receiver. The sampling gate may be used to sample the electron temperature during either the build-up or decay of the plasma. The gated output of the IF amplifier is converted by the pulse smoother and stretcher to a square wave whose amplitude is proportional to the difference in the signals sampled from the two arms of the microwave apparatus. This square-wave signal is fed into the synchronous amplifier, and a null reading is achieved by adjusting the effective noise standard temperature with the calibrated attenuator. Manual adjustment of the calibrated variable delay allows the study of the evolution of the electron temperature during and after the plasma pulse. Such a technique ${ }^{15}$ has been used to study the electron temperature decay in the afterglow of a pulsed discharge in helium. The accuracy of measurement was $\pm 50^{\circ} \mathrm{K}$. Greater sensitivity can be achieved by inserting a low-noise amplifier, such as a parametric or traveling-wave amplifier, into the microwave circuit between the balanced crystal mixer and the isolator. Part of the limitation of the measurement accuracy is due to the slight variations of the discharge from pulse to pulse. 


\section{GENERAL PLASMA DIAGNOSTIC TECHNIQUES}

We shall now discuss various plasma diagnostic techniques other than microwave techniques. In contrast to that of the previous section the purpose of this section will be only to survey these techniques and some of their limitations.

\section{I PLASMA PROBES}

a. The Langmuir Probe and the Double Floating Probe

The Langmuir probe ${ }^{16}$ is in direct electrical contact with the plasma. By observing the current flowing to the probe from the plasma as the probe potential is varied, the electron temperature and density may be determined. When the probe potential is biased positive with respect to the plasma potential, only electrons from the plasma are collected and the current to the probe will be negative. Further increases in the probe potential do not greatly change the current because it is limited to a value determined by the random electron current in the plasma. As the potential is decreased, not all of the electrons are able to reach the probe because of the potential barrier, the number having sufficient energy to reach the probe being proportional to $e^{e V_{p} / k T}$, where $V_{p}$ is the probe potential, and $\mathrm{T}_{\mathrm{e}}$ the electron temperature. For probe potentials sufficiently negative, the probe current has reversed sign, since only the ion current is now collected.

The double floating probe ${ }^{17}$ is a modification of the Langmuir probe, whereby two identical probes, separated by approximately $1 \mathrm{~cm}$, are introduced into the plasma, and the current flowing between them as a function of their potential difference is measured. The double-probe configuration floats electrically with respect to the surrounding plasma, in contrast to the single Langmuir probe. This is advantageous in certain cases, for instance, when the plasma is produced by radiofrequency or microwave breakdown, and the potential at any position in the plasma is not necessarily well defined.

Electronic methods of rapidly sweeping the probe potential through a complete cycle have been developed to allow the study of transient plasma phenomena. Harp ${ }^{18}$ has given such a circuit for the Langmuir probe, and Olsen and Skarsgaard, ${ }^{19}$ using a double probe, have studied a transient helium plasma.

Both single and double probes are useful only at lower pressures where the electron and ion mean-free paths are large compared. with the probe dimensions and with the charge sheath between the probe surface and the neutral plasma. The sheath thickness is of the order of the Debye length; $l_{D}$, which is approximately $\ell_{D} \approx 60 \sqrt{\frac{T}{n}} \mathrm{~cm}$, where $T$ is the electron temperature in ${ }^{\circ} \mathrm{K}$, and $\mathrm{n}$ is the electron density in $\mathrm{cm}^{-3}$. For $\mathrm{T}=10^{4}{ }^{\circ} \mathrm{K}$ and $\mathrm{n}=10^{10} \mathrm{~cm}^{-3}, l_{\mathrm{D}} \approx 0.06 \mathrm{~cm}$. The electron mean-free path in helium is approximately $\frac{.05 \mathrm{~cm}}{\mathrm{p}}$, where $\mathrm{p}$ is the helium pressure in Torr. Hence, the use of the probe above 1-Torr pressure is questionable. Chen ${ }^{20}$ has discussed probe theory and experiment in detail. He includes a discussion of the effect of collisions and the feasibility 
of probe measurements at higher pressures.

\section{b. RF Plasma Probes}

Radiofrequency plasma probes may either take the form of a solenoid surrounding the plasma tube or of a small coil or dipole that is immersed in the plasma. The former method $^{21}$ involves the measurement of the change of impedance of the solenoid because of the presence of the plasma, which can be related to plasma electron density and collision frequency, $v_{\mathrm{m}}$. This method can be applied for pressures $v_{\mathrm{m}} \gg \omega$, in which case the solenoid can be calibrated by using an electrolyte solution of known conductivity. Similar

calibration procedures can be applied to a small coil that is immersed in the plasma. ${ }^{22,23}$ Finally, a metallic probe immersed in the plasma exhibits a resonance ${ }^{24}$ in the collected DC current when the applied frequency equals the electron plasma frequency. This last method can be applied only when the electron collision frequency is much less than the electron plasma frequency.

\subsection{OPTICAL PLASMA DIAGNOSTICS}

Measurement of the optical line spectra ${ }^{25}$ emitted from a plasma can be used to identify the various constituents of the plasma. At lower pressures these lines are broadened by the thermal motion of the emitting particle (Doppler broadening) and by the random electric-field fluctuations (Stark broadening) that are due to the fluctuating charge density around the emitting particle. The Doppler broadening (for the lighter atoms) can be used to determine the temperature of the emitting particles, and the Stark broadening depends primarily on the electron density and only weakly on the electron temperature. At higher pressures broadening effects caused by the perturbations on the emitter of neighboring gas atoms make such line-shape measurements unpractical.

Measurement of the absolute intensity of spectral lines and the absolute intensity. of the continuum emission are two techniques that can be used to determine electron density. The relative intensities of spectral lines or the ratio of the line intensity to the adjacent intensity of the continuum emission can be used to determine electron temperature. These types of measurement generally require that the system be in local thermodynamic equilibrium. That is, that all particle constituents be at the same temperature, and the excited states be populated in a thermal-equilibrium distribution. For the last requirement to be satisfied, the electron density must be sufficiently high that the collisional depopulation rate of the excited states greatly exceeds the rate of radiational depopulation. In the presence of a large neutral particle concentration in the plasma, the condition of local thermodynamic equilibrium may be difficult to satisfy.

The optical continuum emission, in addition to Bremsstrahlung radiation, is due to radiation arising from the capture of free electrons into various excited states of the atoms and ions. The recombination continuum corresponding to a given state in which an electron is captured is distinguished by the presence of a low-frequency cutoff edge corresponding to the capture of a zero-energy free electron. McWhirter ${ }^{26}$ has used the 
frequency dependence of the continuum near these cutoff edges to determine electron temperature in a highly ionized hydrogen plasma.

Measurement of excited-state and ground-state densities is effected by measuring the absorption of a certain frequency line that is transmitted from an external source through the plasma and experiences a resonant absorption by the particle whose density is to be measured. This technique is applicable only when the emission of this same line from the plasma itself does not mask the absorption, as in the afterglow of a pulsed plasma. ${ }^{27}$ The external source is a gas-discharge run in the same mixture of gases as the plasma that is being studied. Determination of absolute densities requires knowledge of the relative line shapes of the emitting and absorbing media (this problem is eliminated if the plasma tubes and plasmas are identical) and of the cross section for absorption. ${ }^{28}$ Determination of relative changes of density of a given species does not require this additional information.

\subsection{OTHER TECHNIQUES}

Some other techniques that might be suitable for plasma diagnostics will be mentioned, along with appropriate references.

The velocities of propagation of acoustic waves ${ }^{29}$ or of ion-acoustic waves are characteristic of the neutral-gas and the electron temperatures, respectively. It is also necessary to know the specific-heat ratio in interpreting the acoustic wave velocity, which may be difficult if complex gas molecules are present. At frequencies of the order of the ion-atom collision frequency the ion-acoustic wave and neutral-acoustic wave couple strongly, ${ }^{30}$ thereby making interpretation difficult.

For the determination of the neutral or charged species identity the following methods might be employed: time-of-flight or magnetic mass spectrometry; molecular resonances $^{31,34}$ at radio and infrared frequencies; ion cyclotron resonance absorption ${ }^{32}$ (applicable only for low charge densities and pressures); and titration ${ }^{33}$ of a flowing plasma by admitting a measured flow of gas to the plasma flow.

\section{Acknowledgment}

The authors wish to thank the Research Laboratory of Electronics of the Massachusetts Institute of Technology whose services and facilities made possible many of the experiments reported in this work, as well as the writing itself. 


\section{BIBLIOGRAPHY}

\section{General Plasma Diagnostic References}

T. P. Anderson, R. W. Springer, and R. C. Warder, Jr. , Physics-Chemical Diagnostics of Plasmas (Northwestern University Press, Evanston, III. , 1963).

H. R. Griem, Plasma Spectroscopy, (McGraw-Hill Book Company, New York, 1964).

M. A. Heald and C. B. Wharton, Plasma Diagnostics with Microwaves (John Wiley and Sons, Inc., New York, 1965).

R. Huddlestone and S. Leonard (eds.) Plasma Diagnostic Techniques (Academic Press, New York, 1965). 


\section{References}

1. S. C. Brown, Basic Data of Plasma Physics (The Technology Press of the Massachusetts Institute of Technology and John Wiley Sons, Inc., New York, 1959), p. 50.

2. For a general reference on microwave design see, for example, Microwave Transmission Design Data by Theodore Moreno (Dover Publications Inc., New York, 1958).

3. S. C. Brown, G. Bekefi, and R. E. Whitney, J. Opt. Soc. Am. 53, 448 (1963); D. T. Llewellyn-Jones, S. C. Brown, and G. Bekefi, Proc. Sixth International Conference on Ionization Phenomena in Gases, Paris, 1963.

4. D. E. T. F. Ashby and D. F. Jephcott, Appl. Phys. Letters 3, 13 (1963); J. B. Gerardo and J. T. Verdeyen, Proc. IEEE 52, 690 (1964).

5. M. A. Biondi and S. C. Brown, Phys. Rev. 75, 1700 (1949).

6. Sanborn C. Brown and David J. Rose, J. Appl. Phys. 23, 711 (1952); David J. Rose and Sanborn C. Brown, J. Appl. Phys. 23, 719 (1952); David J. Rose and Sanborn C. Brown, J. Appl. Phys. 23, 1028 (1952).

7. V. E. Golant, Soviet Phys. - Tech. Phys. 5, 1197 (1961).

8. K. I. Thomassen, J. Appl. Phys. 36,3642 (1965).

9. S. C. Brown, Proc. 2nd International Conference on Peaceful Uses of Atomic Energy (Geneva) 32, 394 (1958).

10. S. J. Buchsbaum and Sanborn C. Brown, Phys. Rev. 106, 196 (1957).

11. Lawrence Gould and Sanborn C. Brown, J. Appl. Phys. 24, 1053 (1953).

12. See, for example, Lawrence Gould and Sanborn C. Brown, Phys. Rev. 95, 897 (1954).

13. M. C. Thompson, Jr. and Frank E. Freethey, National Bureau of Standards Technical Report, NBS 5049.

14. G. Bekefi and S. C. Brown, J. Appl. Phys. 32, 25 (1961).

15. J. C. Ingraham and Sanborn C. Brown, Phys. Rev. 138, A1015 (1965).

16. L. Tonks and I. Langmuir, Phys. Rev. 34, 876 (1929).

17. E. O. Johnson and L. Malter, Phys. Rev. 80,58 (1950).

18. R. S. Harp, Rev. Sci. Instr. 34, 416 (1963).

19. O. D. Olsen and H. M. Skarsgaard, Can. J. Phys. 41,391 (1963).

20. Francis F. Chen, "Electric Probes," in Plasma Diagnostic Techniques, edited by Richard H. Huddlestone and Stanley L. Leonard (Academic Press, New York, 196,5).

21. P. Savic and G. T. Boult, J. Sci. Instr. 39, 258 (1962).

22. C. B. Wharton and R. Hawke, Lawrence Radiation Laboratory Electronics Engineering Report LEL, University of California, Livermore, California, 1962.

23. R. A. Olson and E. C. Lary, Rev. Sci. Instr. 33, 1350 (1962).

24. K. H. Takayama, H. Ikegami, and S. Miyasaki, Phys. Rev. Letters $\underline{5}, 238$ (1960); R. S. Harp and F. W. Crawford, J. Appl. Phys. 35, 3436 (1964).

25. For a general reference on optical plasma spectroscopy see, for example, Plasma Spectroscopy by Hans R. Griem (McGraw-Hill Book Company, New York, 1964).

26. R. W. P. McWhirter, Bull. Am. Phys. Soc. 8 , 164 (1963).

27. A. V. Phelps, Phys. Rev. 99, 1307 (1955).

28. Allan C. G. Mitchell and Mark W. Zemansky, Resonance Radiation and Excited Atoms (Cambridge University Press, London, 1961).

29. Kenneth W. Gentle and Uno Ingard, Appl. Phys. Letters $\underline{5}, 105$ (1964).

30. Lee W. Parker, Phys. Fluids 9, 274 (1966). 
31. See, for a review of work before 1958, M. Kent Wilson and Victor Crawford, Ann. Rev. Phys. Chem. 9, 339 (1958).

32. Darold Wobschall, J. R. Graham, Jr., and K. P. Malone, J. Chem. Phys. 42, 3955 (1965).

33. Frederick Kaufman and John R. Kelso, J. Chem. Phys. 27, 1209 (1957); J. Chem. Phys. 28, 510 (1958).

34. Thomas Marshall and E. A. McLennan, IEEE Trans., Vol. NS-10, p. 124, 1963. 


\section{JOINT SERVICES ELECTRONICS PROGRAM}

REPORTS DISTRIBUTION LIST

Department of Defense

Dr. Edward M. Reilley

Asst Director (Research)

Ofc of Defense Res \& Eng

Department of Defense

Washington, D. C. 20301

Office of Deputy Director

(Research and Information Room 3D1037)

Department of Defense

The Pentagon

Washington, D. C. 20301

Director

Advanced Research Projects Agency

Department of Defense

Washington, D. C. 20301

Director for Materials Sciences

Advanced Research Projects Agency

Department of Defense

Washington, D. C. 20301

Headquarters

Defense Communications Agency (333)

The Pentagon

Washington, D. C. 20305

Defense Documentation Center

Attn: TISIA

Cameron Station, Bldg. 5

Alexandria, Virginia 22314

Director

National Security Agency

Attn: C3/TDL

Fort George G. Meade, Maryland 20755

Weapons Systems Evaluation Group

Attn: Col. Finis G. Johns on

Department of Defense

Washington, D. C. 20305

National Security Agency

Attn: R4-James Tippet

Office of Research

Fort George G. Meade, Maryland 20755

Central Intelligence Agency

Attn: OCR/DD Publications

Washington, D. C. 20505

\section{Department of the Air Force}

AUL3T-9663

Maxwell AFB, Alabama 36112
AFRSTE

Hqs. USAF

Room ID-429, The Pentagon

Washington, D. C. 20330

AFFTC (FTBPP-2)

Technical Library

Edwards AFB, Calif. 93523

Space Systems Division

Air Force Systems Command

Los Angeles Air Force Station

Los Angeles, California 90045

Attn: SSSD

SSD(SSTRT/Lt. Starbuck)

AFUPO

Los Angeles, California 90045

Det \#6, OAR (LOOAR)

Air Force Unit Post Office

Los Angeles, California 90045

Systems Engineering Group (RTD)

Technical Information Reference Branch

Attn: SEPIR

Directorate of Engineering Standards and Technical Information

Wright-Patters on AFB, Ohio 45433

ARL (ARIY)

Wright-Patterson AFB, Ohio 45433

AFAL (AVT)

Wright-Patterson AFB, Ohio 45433

AFAL (AVTE/R. D. Larson)

Wright-Patterson AFB, Ohio 45433

Hq. OAR (RRY) pt

Attn: Col. James A. Fava, USAF

Washington, D. C. 22209 F323

Commanding General

Attn: STEWS-WS-VT

White Sands Missile Range

New Mexico 88002

RADC (EMLAL-1)

Griffiss AFB, New York 13442

Attn: Documents Library

AFCRL (CRMXLR)

AFCRL Research Library, Stop 29

L. G. Hanscom Field

Bedford, Massachusetts 01731 
Academy Library DFSLB)

U.S. Air Force Academy

Colorado 80840

FJSRL

USAF Academy, Colorado 80840

APGC (PGBPS-12)

Eglin AFB, Florida 32542

AFETR Technical Library

(ETV, MU-135)

Patrick AFB, Florida 32925

AFETR (ETLLG-1)

STINFO Officer (for Library)

Patrick AFB, Florida 32925

ESD (ESTI)

L. G. Hanscom Field

Bedford, Massachusetts 01731

AEDC (ARO, INC)

Attn: Library/Documents

Arnold AFS, Tennessee 37389

European Office of Aerospace Research

Shell Building, 47 Rue Cantersteen

Brussels, Belgium

Lt. Colonel Robert B. Kalisch, Chief

Electronics Division F322 5

Directorate of Engineering Sciences

Air Force Office of Scientific Research

1400 Wilson Blvd.

Arlington, Virginia 22209

Department of the Army

U.S. Army Research Office

Attn: Physical Sciences Division 3045 Columbia Pike

Arlington, Virginia 22204

Research Plans Office

U.S. Army Research Office

3045 Columbia Pike

Arlington, Virginia 22204

Commanding General

U.S. Army Materiel Command

Attn: AMCRD-DE-E

Washington, D.C. 20315

Commanding General

U.S. Army Strategic Communications Command

Washington, D. C. 20315
Commanding Officer

U.S. Army Materials Research Agency

Watertown Arsenal

Watertown, Massachusetts 02172

Commanding Officer

U.S. Army Ballistics Research Laboratory

Attn: V. W. Richards

Aberdeen Proving Ground

Aberdeen, Maryland 21005

Commandant

U.S. Army. Air Defense School

Attn: Missile Sciences Division C\&S Dept.

P.O. Box 9390

Fort Bliss, Texas 79916

Commanding General

Frankford Arsenal

Attn: SMFA-L6000-64-4 (Dr. Sidney Ross)

Philadelphia, Pennsylvania 19137

Commanding General

U.S. Army Missile Command

Attn: Technical Library

Redstone Arsenal, Alabama 35809

U.S. Army Munitions Command

Attn: Technical Information Branch

Picatinney Arsenal

Dover, New Jersey 07801

Commanding Officer

Harry Diamond Laboratories

Attn: Mr. Berthold Altman

Connecticut Avenue and Van Ness St. N. W.

Washington, D. C. 20438

Commanding Officer

U.S. Army Security Agency

Arlington Hall

Arlington, Virginia 22212

Commanding Officer

U.S. Army Limited War Laboratory

Attn: Technical Director

Aberdeen Proving Ground

Aberdeen, Maryland 21005

Commanding Officer

Human Engineering Laboratories

Aberdeen Proving Ground, Maryland 21005

Director

U.S. Army Engineer

Geodesy, Intelligence and Mapping

Research and Development Agency

Fort Belvoir, Virginia 22060 


\section{JOINT SERVICES REPORTS DISTRIBUTION LIST (continued)}

Commandant

U.S. Army Command and General Staff College

Attn: Secretary

Fort Leavenworth, Kansas 66270

Dr. H. Robl, Deputy Chief Scientist

U.S. Army Research Office (Durham)

Box CM, Duke Station

Durham, North Carolina 27706

Commanding Officer

U.S. Army Research Office (Durham)

Attn: CRD-AA-IP (Richard O. Ulsh)

Box CM. Duke Station

Durham, North Carolina 27706

Superintendent

U.S. Army Military Academy

West Point, New York 10996

The Walter Reed Institute of Research

Walter Reed Medical Center

Washington, D. C. 20012

Commanding Officer

U.S. Army Engineer R\&D Laboratory

Attn: STINFO Branch

Fort Belvoir, Virginia 22060

Commanding Officer

U.S. Army Electronics R\&D Activity

White Sands Missile Range,

New Mexico 88002

Dr. S. Benedict Levin, Director Institute for Exploratory Research U.S. Army Electronics Command

Attn: Mr. Robert O. Parker, Executive Secretary, JSTAC (AMSEL-XL-D)

Fort Monmouth, New Jersey 07703

Commanding General

U.S. Army Electronics Command

Fort Monmouth, New Jersey 07703

Attn: AMSEL-SC

$\begin{array}{cc}\text { AMSEL-RD-D } & \text { HL-O } \\ \text { RD-G } & \text { HL-R } \\ \text { RD-MAF-1 } & \text { NL-D } \\ \text { RD-MAT } & \text { NL-A } \\ \text { RD-GF } & \text { NL-P } \\ \text { XL-D } & \text { NL-R } \\ \text { XL-E } & \text { NL-S } \\ \text { XL-C } & \text { KL-D } \\ \text { XL-S } & \text { KL-E } \\ \text { HL-D } & \text { KL-S } \\ \text { HL-L } & \text { KL-T } \\ \text { HL-J } & \text { VL-D } \\ \text { HL-P } & \text { WL-D }\end{array}$

Department of the Navy

Chief of Naval Research

Department of the Navy

Washington, D. C. 20360

Attn: Code 427

Chief, Bureau of Ships

Department of the Navy

Washington, D.C. 20360

Chief, Bureau of Weapons

Department of the Navy

Washington, D. C. 20360

Commanding Officer

Office of Naval Research Branch Office

Box 39, Navy No 100 F.P.O.

New York, New York 09510

Commanding Officer

Office of Naval Research Branch Office

1030 East Green Street

Pasadena, California

Commanding Officer

Office of Naval Research Branch Office

219 South Dearborn Street

Chicago, Illinois 60604

Commanding Officer

Office of Naval Research Branch Office 207 West 42nd Street

New York, New York 10011

Commanding Officer

Office of Naval Research Branch Office 495 Summer Street

Boston, Massachusetts 02210

Director, Naval Research Laboratory

Technical Information Officer

Washington, D. C.

Attn: Code 2000

Commander

Naval Air Development and Material Center

Johnsville, Pennsylvania 18974

Librarian, U.S. Electronics Laboratory.

San Diego, California 95152

Commanding Officer and Director

U.S. Naval Underwater Sound Laboratory.

Fort Trumbull

New London, Connecticut 06840

Librarian, U.S. Naval Post Graduate School

Monterey, California 
Commander

U.S. Naval Air Missile Test Center

Point Magu, California

Director

U.S. Naval Observatory

Washington, D. C.

Chief of Naval Operations

OP-07

Washington, D. C.

Director, U.S. Naval Security Group

Attn: G43

3801 Nebraska Avenue

Washington, D. C.

Commanding Officer

Naval Ordnance Laboratory

White Oak, Maryland

Commanding Officer

Naval Ordnance Laboratory

Corona, California

Commanding Officer

Naval Ordnance Test Station

China Lake, California

Commanding Officer

Naval Avionics Facility

Indianapolis, Indiana

Commanding Officer

Naval Training Device Center

Orlando, Florida

U.S. Naval Weapons Laboratory

Dahlgren, Virginia

Weapons Systems Test Division

Naval Air Test Center

Patuxtent River, Maryland

Attn: Library

\section{Other Government Agencies}

Mr. Charles F. Yost

Special Assistant to the Director NASA of Research

Washington, D. C. 20546

NASA Lewis Research Center

Attn: Library

21000 Brookpark Road

Cleveland, Ohio 44135
Dr: H. Harrison, Code RRE

Chief, Electrophysics Branch

NASA, Washington, D. C. 20546

Goddard Space Flight Center NASA

Attn: Library, Documents Section Code 252

Green Belt, Maryland 20771

National Science Foundation

Attn: Dr. John R. Lehmann

Division of Engineering, 1800 G Street N.W.

Washington, D.C. 20550

U. S. Atomic Energy Commission

Division of Technical Information Extension

P.O. Box 62, Oak Ridge, Tennessee 37831

Los Alamos Scientific Library

Attn: Reports Library

P. O. Box 1663

Los Alamos, New Mexico 87544

NASA Scientific \& Technical Information Facility

Attn: Acquisitions Branch (S/AK/DL)

P. O. Box 33, College Park, Maryland 20740

NASA Langley Research Center G-108

Langley Station, Hampton, Virginia 23365

Attn: Mr. R.V. Hess, Mail Stop 160

Non-Government Agencies

Director

Research Laboratory of Electronics

Massachusetts Institute of Technology

Cambridge, Massachusetts 02139

Polytechnic Institute of Brooklyn

55 Johnson Street

Brooklyn, New York 11201

Attn: Mr. Jerome Fox

Research Coordinator

Director

Columbia Radiation Laboratory

Columbia University

538 West 120th Street

New York, New York 10027

Director

Stanford Electronics Laboratories

Stanford University

Stanford, California

Director

Coordinated Science Laboratory

University of Illinois

Urbana, Illinois 61803 


\section{Director}

Electronics Research Laboratory

University of California

Berkeley 4, California

Director

El ectronics Sciences Laboratory

University of Southern California

Los Angeles, California 90007

Professor A. A. Dougal, Director Laboratories for Electronics and Related Sciences Research

University of Texas

Austin, Texas 78712

Division of Engineering and Applied Physics

210 Pierce Hall

Harvard University

Cambridge, Massachusetts 02138

Aerospace Corporation

P.O. Box 95085

Los Angeles, California 90045

Attn: Library Acquisitions Group

Professor Nicholas George

California Institute of Technology

Pasadena, California

Aeronautics Library

Graduate Aeronautical Laboratories

California Institute of Technology

1201 E. California Blvd.

Pasadena, California 91109

Director, USAF Project RAND

Via: Air Force Liaison Office

The RAND Corporation

1700 Main Street

Santa Monica, California 90406

Attn: Library

The Johns Hopkins University

Applied Physics Laboratory

8621 Georgia Avenue

Silver Spring, Maryland

Attn: Boris W. Kuvshinoff Document Librarian

School of Engineering Sciences

Arizona State University

Tempe, Arizona

Dr. Leo Young

Stanford Research Institute

Menlo Park, California
Hunt Library

Carnegie Institute of Technology.

Schenley Park

Pittsburgh, Pennsylvania 15213

Mr. Henry L. Bachmann

Assistant Chief Engineer

Wheeler Laboratories

122 Cuttermill Road

Great Neck, New York

University of Liege

Electronic Institute

15. Avenue Des Tilleuls

Val-Benoit, Liege

Belgium

University of California at Los Angeles

Department of Engineering

Los Angeles, California

California Institute of Technology

Pasadena, California

Attn: Documents Library

University of California

Santa Barbara, California

Attn: Library

Carnegie Institute of Technology

Electrical Engineering Department

Pittsburgh, Pennsylvania

University of Michigan

Electrical Engineering Department

Ann Arbor, Michigan

New York University

College of Engineering

New York, New York

Syracuse University

Dept. of Electrical Engineering

Syracuse, New York

Yale University

Engineering Department

New Haven, Connecticut

Bendix Pacific Division

11600 Sherman Way

North Hollywood, California

General Electric Company

Research Laboratories

Schenectady, New York 
JOINT SERVICES REPORTS DISTRIBUTION LIST (continued)

Airborne Instruments Laboratory

Deerpark, New York

Lockheed Aircraft Corporation

P.O. Box 504

Sunnyvale, California

Raytheon Company

Bedford, Massachusetts

Attn: Librarian 
Ǔnclassified

Security Classification

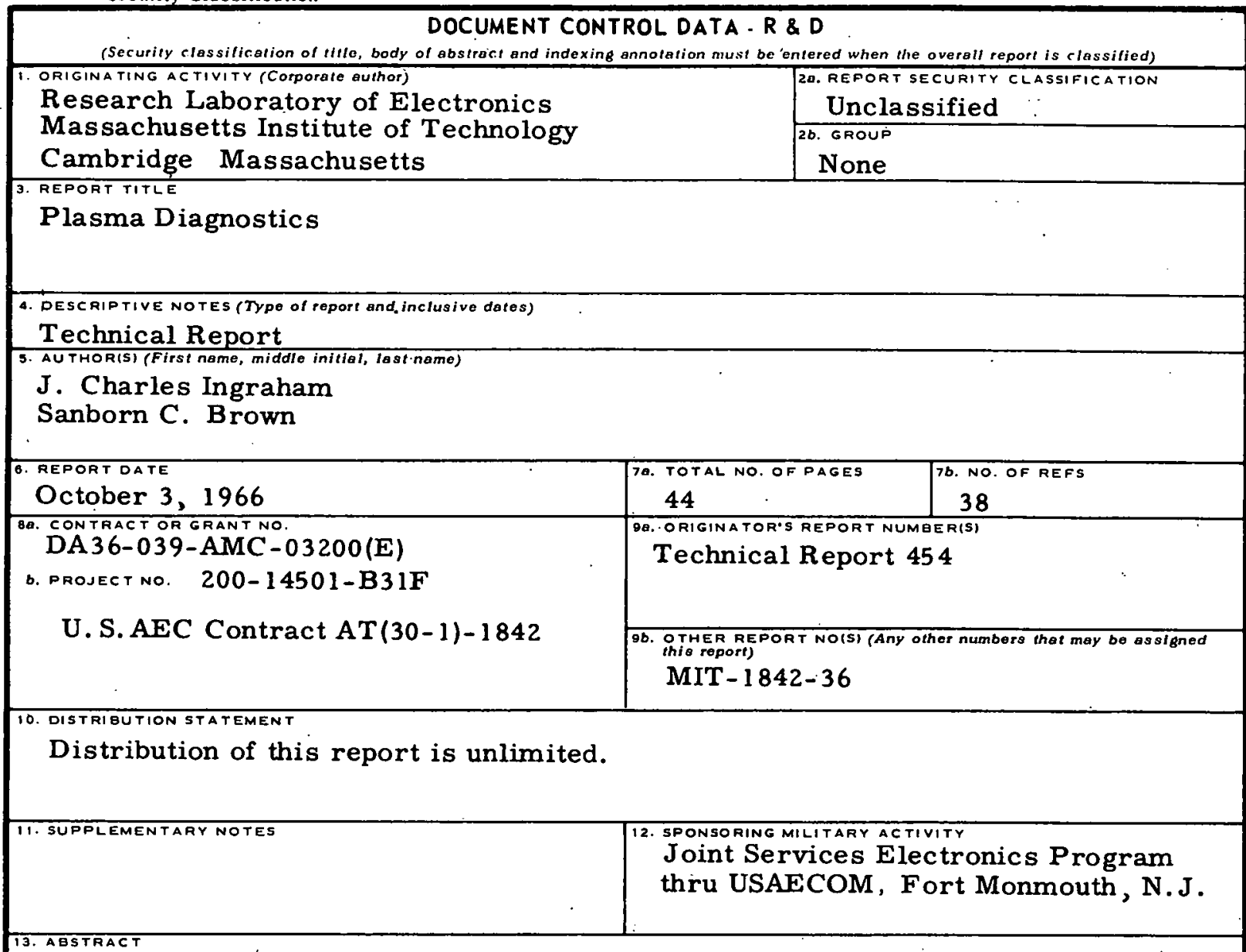

This report is designed to provide a practical description of laboratory microwave techniques for studying plasmas, as well as to mention briefly other techniques that can be used in plasma studies.

DD , FORM 1473 (PAGE 1 )

$S / N D 101-807-6811$
Unclassified

Security Classification 
Unclassified

Security Classification

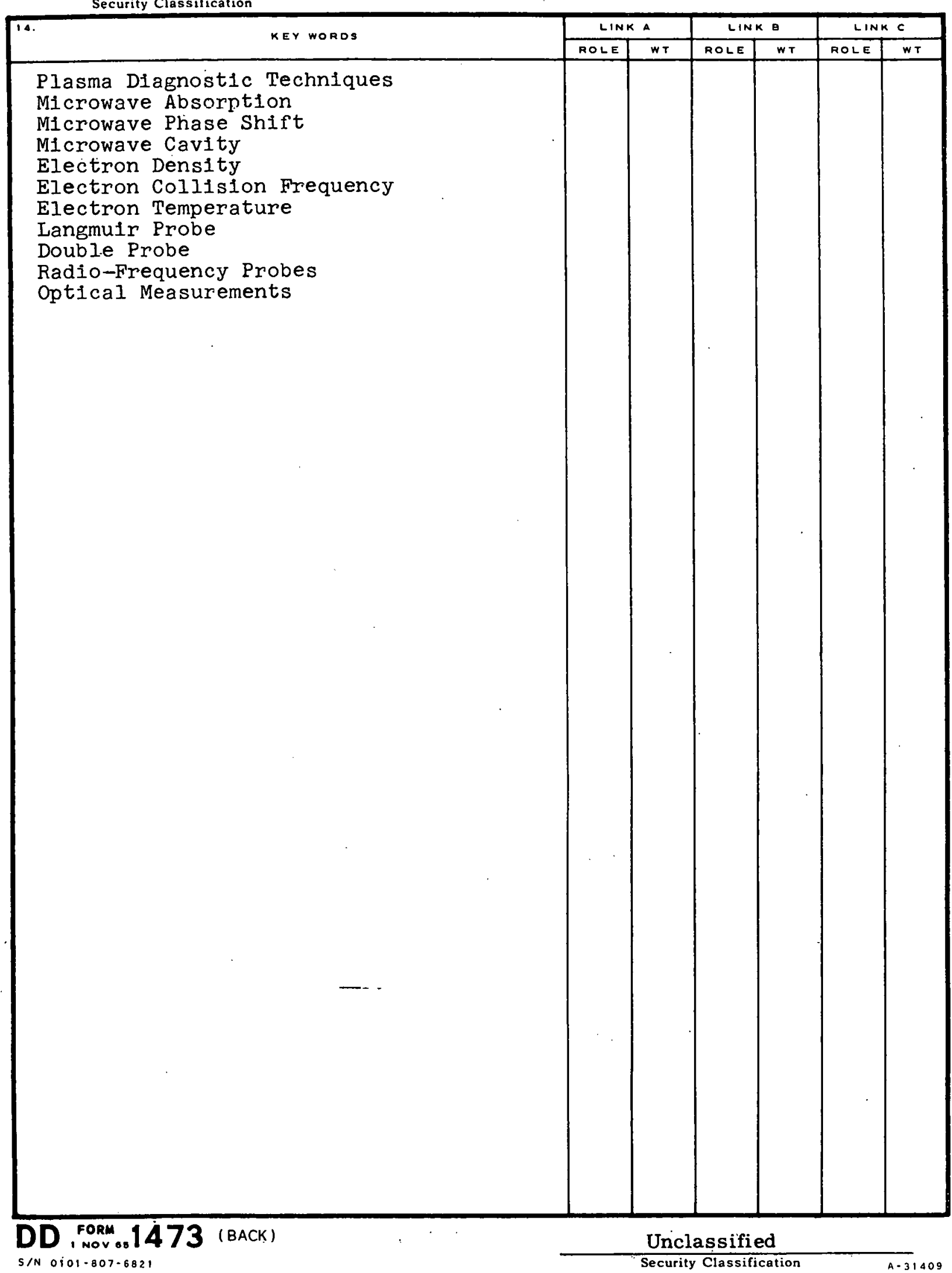

